\title{
Breach remedies, reliance and renegotiation
}

Citation for published version (APA):

Riedl, A. M., Sloof, R., Oosterbeek, H., \& Sonnemans, J. J. (2006). Breach remedies, reliance and renegotiation. International Review of Law and Economics, 26, 263-296.

https://doi.org/10.1016/j.irle.2006.11.002

Document status and date:

Published: 01/01/2006

DOI:

10.1016/j.irle.2006.11.002

Document Version:

Publisher's PDF, also known as Version of record

Document license:

Taverne

Please check the document version of this publication:

- A submitted manuscript is the version of the article upon submission and before peer-review. There can be important differences between the submitted version and the official published version of record.

People interested in the research are advised to contact the author for the final version of the publication, or visit the DOI to the publisher's website.

- The final author version and the galley proof are versions of the publication after peer review.

- The final published version features the final layout of the paper including the volume, issue and page numbers.

Link to publication

\footnotetext{
General rights rights.

- You may freely distribute the URL identifying the publication in the public portal. please follow below link for the End User Agreement:

www.umlib.nl/taverne-license

Take down policy

If you believe that this document breaches copyright please contact us at:

repository@maastrichtuniversity.nl

providing details and we will investigate your claim.
}

Copyright and moral rights for the publications made accessible in the public portal are retained by the authors and/or other copyright owners and it is a condition of accessing publications that users recognise and abide by the legal requirements associated with these

- Users may download and print one copy of any publication from the public portal for the purpose of private study or research.

- You may not further distribute the material or use it for any profit-making activity or commercial gain

If the publication is distributed under the terms of Article $25 \mathrm{fa}$ of the Dutch Copyright Act, indicated by the "Taverne" license above, 


\title{
Breach remedies, reliance and renegotiation
}

\author{
Randolph Sloof ${ }^{\mathrm{a}, *}$, Hessel Oosterbeek ${ }^{\mathrm{a}}$, \\ Arno Riedl ${ }^{\mathrm{b}}$, Joep Sonnemans ${ }^{\mathrm{a}}$ \\ a School of Economics, University of Amsterdam, Roetersstraat 11, \\ 1018 WB Amsterdam, The Netherlands \\ ${ }^{\mathrm{b}}$ IZA and Maastricht University, Department of Economics 1, Faculty of Economics and Business \\ Administration, Maastricht University, P.O. Box 616, 6200 MD Maastricht, The Netherlands
}

\begin{abstract}
Breach remedies can be used to protect specific investments and are therefore a remedy against holdup. Yet some commonly used remedies are predicted to provide too much protection, thereby inducing overinvestment. Two motives drive this prediction: the insurance motive and the separation prevention motive. This paper presents results from an experiment designed to test whether these two motives show up in practice. In contrast to previous experiments the focus is on a setting where ex post renegotiations are possible. Our results indicate that also in this case the insurance motive and the separation prevention motive are at work, as predicted. A second main finding is that there seems less need for sophisticated breach remedies based on compensatory money damages than is suggested by theory.

(c) 2006 Elsevier Inc. All rights reserved.
\end{abstract}

JEL classification: $\mathrm{K} 12 ; \mathrm{J} 41 ; \mathrm{C} 91$

Keywords: Contracts; Specific performance; Liquidated damages; Expectation damages; Reliance damages; Experiments

* Corresponding author. Tel.: +31 205255 241; fax.: +31 205254310.

E-mail address: r.sloof@uva.nl (R. Sloof). 


\section{Introduction}

Contracts are valuable because they provide commitment to the parties that signed the agreement. This commitment is created through the (implicit) specification of what happens if one of the parties fails to perform. Breach remedies make this explicit. They specify how to calculate the amount of compensation the defaulting party has to pay. In this paper we focus on the four most prominent types of breach remedies (cf. Posner, 1977, Cooter \&Ulen, 1997, Edlin, 1998):

- liquidated damages: the breacher has to pay a fixed amount to the victim of breach. The amount to be paid is specified in the initial contract;

- expectation damages: the breacher has to pay the amount that makes the victim equally well off as under contract performance;

- reliance damages: the breacher compensates the victim such that the latter is equally well off as before the contract had been signed;

- specific performance: breach of contract is not possible. An agent is required to stay in the relation if the other party asks him to do so.

The first three remedies all specify a sum of money that the breacher has to pay to the innocent party. This expresses a "liability rule", which is common under Anglo-American common law and uncommon in civil law systems. In contrast, the remedy of specific performance corresponds to a "property rule". This is common in civil law systems but rare in common law systems (cf. Ulen, 1998).

Breach remedies play an important role in protecting (non-contractable) relationshipspecific investments. ${ }^{1}$ Without contractual commitment, underinvestment is likely to occur because of holdup (cf. Klein, Crawford, \& Alchian, 1978, Williamson, 1985). Holdup entails that, after reliance expenditures are made, the other party may behave opportunistically by threatening to terminate the relationship. Such a threat permits this party to obtain better terms of trade than were initially agreed upon and thereby to capture some of the returns on the specific investment made by the other party. Anticipating that she may be unable to reap the full return, the investor will invest less than the efficient level. Breach remedies can be used to overcome this holdup underinvestment problem, because they effectively protect the investor against appropriation of the return on the investment by the trading party.

The theoretical literature predicts that breach remedies typically provide too much protection, thereby causing overreliance. Two distinct motives drive such overinvestment. First, with the exception of liquidated damages, the above breach remedies effectively insure the investor against separation. She still gets some private return on the investment made, even when it is efficient for the parties to separate and the specific investment has no social return. This is the insurance motive; the investor is insured against states in which a third party has a higher valuation for the good (and therefore buys it in the end). The second motive

\footnotetext{
${ }^{1}$ These are investments that are profitable only in the event of contract performance and they are, within the law and economics literature, usually referred to as reliance expenditures. In this paper we use the terms (specific) investment and reliance interchangeably.
} 


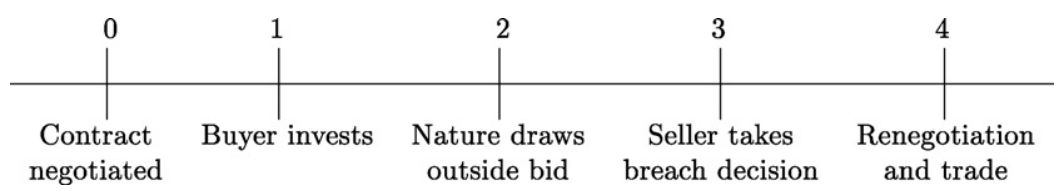

Fig. 1. Timing of events in the holdup game.

to overinvest is only operative under reliance damages. In this case the investor is better off when the parties trade than when they efficiently separate. She may therefore have an incentive to invest at least so much such that the valuation within the relationship exceeds the highest possible valuation of an outside party. This is the separation prevention motive. Only liquidated damages that are set at an appropriate level can avoid both overinvestment motives and provide the investor with the incentive to invest the efficient amount. All these predictions hold irrespective of whether the initial contract can be renegotiated ex post, or not; see Rogerson (1984) and Shavell (1980), respectively.

Whether the various breach remedies perform as theory predicts and indeed cause overreliance is an empirical issue. In an earlier experimental study Sloof, Leuven, Oosterbeek, and Sonnemans (2003) take a first step in investigating this. They establish that the two overinvestment motives are indeed operative in a setting without renegotiation. Their experiment serves as point of departure for the present one. In particular, in this paper we extend the experiment of Sloof et al. by allowing for ex post renegotiation. This makes the experimental setting much more realistic (see below).

The timing of events in the game that we study is represented in Fig. 1. The game relates to a bilateral trading situation between a female Buyer and a male Seller over one unit of a particular good. At time 0 the parties sign a contract that specifies a fixed price at which they will trade. This fixed price cannot be conditioned on Buyer's investment decision. Subsequently, at time 1, Buyer makes an investment that increases her valuation of the good. Afterwards, at time 2, the parties learn for how much Seller can sell his unit to an alternative buyer. When this outside bid is known, Seller decides at time 3 whether to stick to the initial contract and to sell his unit to Buyer, or to breach the contract. When Seller decides to breach, he has to pay damages to Buyer. In either case - both after breach and after no breach - Buyer and Seller have the opportunity to renegotiate at time 4 the terms of trade and separation, respectively.

The experiments reported in Sloof et al. (2003) capture stages $0-3$, but omit stage $4 .^{2}$ The main findings are that observed investment levels closely follow the theoretical predictions. Appropriately designed liquidated damages do not induce overinvestment, as predicted. In case of expectation damages, the insurance motive to overinvest indeed appears to be operative. And in case of reliance damages, both the insurance and the separation prevention motive are at work. The remedy of specific performance was not considered in this earlier study.

\footnotetext{
${ }^{2}$ In the actual design of the experiments the initial contract is pre-determined for the subjects, implying that the game they play also effectively omits stage 0 . The same procedure is employed in the current paper.
} 
In the present experiment we add stage 4 to the game. ${ }^{3}$ This enables a test of the theoretical prediction that adding a renegotiation stage does not affect investment incentives. This is important for two reasons. First, allowing for renegotiation is much more realistic. In practice it is highly unlikely that the interaction between the contracting parties ends with a breach decision when this decision results in an inefficient outcome. In case it appears ex post that parties can gain from renegotiation, they are likely to do so. Parties typically cannot credibly commit not to renegotiate inefficient outcomes (cf. Edlin \& Hermalin, 2000).

A second motivation for adding the renegotiation stage is that bargaining inefficiencies may have a profound effect on investment incentives. Most of the existing theoretical work considers the holdup problem in settings where ex post renegotiations take place under symmetric information. Bargaining inefficiencies are then predicted not to occur in equilibrium. By construction such losses are also absent in Sloof et al. (2003). Yet it is well-known from both laboratory experiments and field data that in practice renegotiations often do cause substantial efficiency losses, even when bargaining takes place under symmetric information. This may in turn affect investment incentives. For example, one could reasonably expect less overinvestment, because the investor realizes that some of the (social) returns on investment leak away in protracted bargaining. Recent theoretical work by Lau (2002) on holdup under asymmetric information has shown that bargaining inefficiencies can actually be good for investment incentives. A similar result may be observed in practice under symmetric information when bargaining brings about (theoretically unpredicted) inefficiencies.

The main findings of this paper are two-fold. First, the two overinvestment motives are also present in the setup with ex post renegotiation, again causing overreliance. In line with theoretical predictions the insurance motive is present under reliance damages, expectation damages and specific performance. And the separation prevention motive is indeed operative under reliance damages only. Together with the earlier results obtained for the no-renegotiation setup, our current findings reveal that the two overinvestment motives are very robust.

Second, our results suggest that there is no strong need for sophisticated breach remedies based on compensatory money damages. Realized efficiency is higher either in the absence of a contract or under specific performance, compared with the three remedies of liquidated damages, reliance damages and expectation damages. ${ }^{4}$ In particular, when the probability of a high outside bid is low and separation therefore unlikely to be efficient, none of these three remedies performs better than specific performance. In the opposite case where the probability of a high outside bid is high, breach remedies do not induce higher efficiency

\footnotetext{
${ }^{3}$ Our ordering of stages 3 and 4 follows Che and Chung (1999). The reason for this is two-fold. First, it makes the present experiment better comparable with the benchmark study of Sloof et al. (2003). Second, in practice parties typically cannot threat not to renegotiate inefficient outcomes (cf. Edlin \& Hermalin, 2000). Because the breach decision itself may result in an inefficient outcome, one therefore should allow for renegotiations after Seller's breach decision. A more elaborate justification for the particular timing we use is given in Appendix B.1, which can be downloaded from the first author's website: www1.fee.uva.nl/scholar/mdw/sloof/.

${ }^{4}$ The latter three remedies are labeled 'sophisticated', because their implementation relies on a careful determination of the exact amount that has to be paid. As noted before, the sophisticated breach remedies correspond to an entitlement (to Seller's good) protected by a liability rule, while specific performance is equivalent to an entitlement protected by a property right. The literature on the protection of entitlements (see e.g. Bebchuk (2002) and Croson and Johnston (2000)) is thus closely related.
} 
levels than under no contract. The main reason for this is that without a contract holdup appears less of a problem than theory predicts.

Our findings add to the debate on optimal breach remedies in contracts. As already mentioned above, according to standard theory the remedy of liquidated damages has the potential of providing parties with the proper investment incentives. In light of this, Mahoney(2000, p. 127) finds it puzzling that courts will often not enforce liquidated damage clauses. Our empirical results suggest that this behavior of courts may be less inefficient than Mahoney suggests; in practice liquidated damages may perform less well than theory predicts. In line with Jolls, Sunstein, and Thaler (1998), a more behavioral approach to breach remedies and holdup thus seems warranted.

In the experiment the probability distribution of outside bids is exogenously given. In reality this is not the case, because contracting partners are endogenously chosen. In making their choice parties will typically look for a contracting partner with whom trade is likely to be efficient. From this perspective our treatment in which separation is unlikely to be efficient is the more realistic and interesting one. The findings for this treatment then point at the attractiveness - i.e. small inefficiency losses - of using specific performance.

Various legal scholars have built a case for the use of specific performance based on efficiency grounds, see Mahoney (2000) and Ulen (1998) for overviews. The theoretical argument put forward is that in practice compensatory money damages are likely to be under-compensatory. As Ulen (1998) puts it:

“... in practice, there may be an efficiency advantage for specific performance as the default remedy. This is due to the possibility of court error in accurately computing expectation damages and the current legal limitations on the ability of contracting parties to specify liquidated damages. ... Until we have compelling empirical evidence, the choice between specific performance and legal relief [i.e. compensatory money damages], ... turns on one's comparative estimate of the risk of error from parties' failure to reach an efficient outcome under specific performance and the risk of error in a court's estimating damages (plus the costs of litigation)."

In our experiment the informational problems attached to sophisticated breach remedies are absent by construction. Even then it appears that, given actually observed behavior, specific performance may perform best from an efficiency perspective. We feel that this finding makes "the case for specific performance" (cf. Schwartz, 1979) more compelling.

The remainder of the paper is organized as follows. In Section 2 we discuss the basic setup of the experimental game and derive the equilibrium predictions for the three breach remedies based on compensatory money damages. Section 3 presents the experimental design, while Section 4 reports the results. In Section 5 we investigate what happens in the absence of sophisticated damage payments. In particular, we present the results for the two polar cases of no contract and specific performance. In both cases there is no breach decision stage, because in the absence of a contract there is simply no contract that can be breached whereas under specific performance breach is explicitly excluded. Section 6 compares all five different cases in terms of efficiency. The final section summarizes our main findings and concludes. 


\section{Sophisticated breach remedies}

\subsection{Basic setup of the model}

In this subsection we provide a precise description of the game reflected in Fig. 1. For ease of exposition this description is cast in terms of the specific parameter values that are used in the experiment. ${ }^{5}$

Two risk neutral parties, labeled Buyer and Seller, may trade one unit of a particular good. Before actual trade takes place, Buyer can make a specific investment $I$ that increases her valuation of Seller's product. Production costs are normalized to zero. Seller may also sell his single unit outside the relationship at a fixed price. This outside bid is unknown at the time Buyer decides on her reliance expenditure. It can either be low or high. The probability that the latter case applies is used as a treatment variable. The game now has the following specific setup and sequence of events:

0. Contracting stage. Buyer and Seller sign a contract specifying that trade takes place at fixed price $4 \cdot f=4 \cdot(600),{ }^{6}$ and also include a damage schedule $4 \cdot \delta(I)$ in the contract;

1. Investment stage. Buyer makes a specific investment $I \in\{0,5,10, \ldots, 100\}$. The size of the investment determines Buyer's valuation of the good, which equals $4 \cdot R(I)=4$. $(1000+100 \cdot I)$. Investment costs equal $4 \cdot C(I)=4 \cdot\left(I^{2}\right)$ and are immediately borne by Buyer;

2. Nature draws outside bid. The value of Seller's alternative trading opportunity $b \in$ $\{0,7000\}$ becomes publicly known. The prior probability that $b=7000$ equals either $p=(1 / 5)$ (Low-treatment) or $p=(3 / 5)$ (High-treatment);

3. Breach decision stage. Seller decides whether to breach the contract or not. This decision determines the gross surplus up for renegotiation $R S$ and the threat points $T P_{i}$ (for $i=\mathrm{S}, \mathrm{B})$ that apply in every round of the bargaining stage, see stage 4 below. If Seller breaches, it holds that:

$$
\mathrm{RS}=R(I), \mathrm{TP}_{\mathrm{B}}=\delta(I) \text { and } \mathrm{TP}_{\mathrm{S}}=b-\delta(I),
$$

and if Seller does not breach, we have:

$$
\mathrm{RS}=b, \mathrm{TP}_{\mathrm{B}}=R(I)-f \text { and } \mathrm{TP}_{\mathrm{S}}=f ;
$$

4. Bargaining stage. Buyer and Seller first simultaneously decide whether they want to renegotiate or not. Only when both agree to do so, actual renegotiations take place. In that case Buyer and Seller alternate in making offers up to a maximum of four bargaining

\footnotetext{
5 Appendix B, available at the first author's website, discusses a more general specification of the model and also formally derives the equilibrium predictions.

${ }^{6}$ Hence $f=600$. The interpretation of the factor 4 will become clear below when we discuss the players' payoffs. Note that the initial contract is pre-determined and cannot be chosen by the parties themselves. A full analysis for any contract price $f$ can be found in Appendix B (available on the web).
} 
rounds, of how to divide four equally sized pies of size RS. Seller makes the first offer. In case of acceptance all remaining pies - including the one of the current round - are divided according to the proposal agreed upon. During a round of disagreement the pie of that round vanishes and both parties receive their threat point payoffs. When parties decide not to renegotiate Buyer and Seller obtain four times their threat point payoffs.

The overall payoffs $\Pi_{\mathrm{B}}$ and $\Pi_{\mathrm{S}}$ of Buyer and Seller depend on the absolute share $s$ Seller receives of the round pie of size RS, and on the bargaining round $t$ during which parties reach agreement (in case of no renegotiations or no agreement $t=5$ ):

$$
\begin{aligned}
& \Pi_{\mathrm{B}}=(5-t) \cdot(\mathrm{RS}-s)+(t-1) \cdot \mathrm{TP}_{\mathrm{B}}-4 \cdot C(I) \\
& \Pi_{\mathrm{S}}=(5-t) \cdot s+(t-1) \cdot \mathrm{TP}_{\mathrm{S}}
\end{aligned}
$$

For ease of exposition we will in the sequel always work with the average payoffs per bargaining round. These are given by $\pi_{i}=\Pi_{i} / 4$ for $i=\mathrm{B}, \mathrm{S}$. Note that the number of bargaining rounds just works as a scaling factor. For any even number of bargaining rounds the equilibrium predictions concerning investment levels and the division of the surplus are exactly the same (cf. Sloof, 2004). By considering the average payoffs per bargaining round all results become directly comparable with those in Sloof et al. (2003) where exactly the same parameterization for $R(I), C(I), f$ and $b$ is used.

Intuitively the order of play can be interpreted as follows. At the start of the game the status quo is trade according to the terms of the initial contract; Seller sells to Buyer at a fixed price of $f=600$. After the outside bid becomes known Seller may change this status quo outcome into separation, just by breaching the contract and paying $\delta(I)$ to Buyer. This change may be attractive for Seller, either because separation itself is more profitable, or because it induces a profitable (i.e. upwards) renegotiation of the initial trade price of 600 . Hence, breach of contract does not necessarily lead to separation, because the parties may renegotiate this decision into trade. The same applies when Seller decides not to breach. This does not necessarily lead to trade, because parties may renegotiate into separation at a lower damage payment. In general, the parties can renegotiate the outcome of Seller's breach decision to arrive at the ex post efficient outcome.

The three sophisticated breach remedies that we study are characterized by the following damage payments:

- Liquidated damages (LI): $\delta_{L I}(I)=\delta_{\mathrm{LI}}=3400$;

- Expectation damages (EX): $\delta_{\mathrm{EX}}(I)=R(I)-f=R(I)-600$;

- Reliance damages (RE): $\delta_{\mathrm{RE}}(I)=C(I)=I^{2}$.

The main question of interest is whether these damage payments create efficient investment incentives. Our parameter choices are such that (for the efficient investment level) trade is efficient when $b=0$, while separation is efficient when $b=7000$. From a social point of view the investment thus only pays off when $b=0$. It is straightforward to derive that the efficient level equals $I^{*}=40$ in the Low-treatment $(p=1 / 5)$ and $I^{*}=20$ in the Hightreatment $(p=3 / 5)$. Note that the efficient reliance level is decreasing in $p$. Comparative statics in $p$ will play an important role in detecting the two motives to overinvest. 


\subsection{Equilibrium predictions}

The subgame perfect equilibria of the game described in the previous subsection can be obtained through backwards induction. In this subsection we provide a more intuitive explanation of equilibrium behavior. ${ }^{7}$ We do so by comparing the current setup with the one in which the renegotiation stage is absent.

First suppose that renegotiation is not possible. The game then ends with Seller's breach decision in stage 3. In that case, when Seller does not breach he obtains the fixed price $f$. In case of breach he sells his single unit to the outside buyer at price $b$, but also has to pay the original Buyer $\delta(I)$ in damages. Seller thus chooses to breach if $f<b-\delta(I){ }^{8}$

Next consider what happens in the presence of ex post renegotiation. When the breach decision of Seller induces the efficient outcome - i.e. trade when $R(I) \geq b$ and no-trade in case $b>R(I)$ - renegotiations will not take place. This holds because no agreement exists that makes both Buyer and Seller better off. In case Seller's breach decision would lead to an inefficient outcome, such mutually beneficial agreements do exist. Theory predicts that then renegotiations will take place. The predicted outcome of the particular bargaining game employed coincides with the Nash bargaining solution (cf. Sloof, 2004). This entails that both parties receive their threat point payoffs and that the remaining surplus is divided equally. This is often referred to as the split-the-difference solution.

Obviously, Seller's breach decision changes in the presence of renegotiation. He now also has to take into account that inefficient outcomes are renegotiated into efficient ones, yielding him an additional benefit. In particular, no breach will yield him now $f+(1 / 2)$. $\max \{b-R(I), 0\}$. The second term follows from the fact that when separation is efficient, Seller's decision not to breach will be renegotiated into separation. The joint gains $b-R(I)$ from doing so are then shared equally. Similarly, breach leads to payoffs equal to $b-\delta(I)+$ $(1 / 2) \cdot \max \{R(I)-b, 0\}$ for Seller. Here the second term follows from renegotiating an inefficient breach. Comparing the two payoffs, it follows that Seller breaches whenever:

$$
f<b-\delta(I)+\frac{1}{2} \cdot(R(I)-b)
$$

Compared to the no-renegotiation case the last term on the r.h.s. is added. Breach thus becomes relatively more (less) attractive when $b$ is low (high).

Under what circumstances Seller breaches depends on the damage payment $\delta(I)$ in place. In case of liquidated damages (LI) the breach decision depends on the exact amount $\delta_{\mathrm{LI}}$. Three main cases can be distinguished. First, for a sufficiently low fixed payment, Seller breaches both when $b$ is low and when $b$ is high. Second, for a sufficiently high fixed payment, Seller never breaches. ${ }^{9}$ Third, the fixed payment can equal an intermediate value such that Seller breaches only when $b$ is high. Our choice of $\delta_{L I}=3400$ fits within this

\footnotetext{
7 The formal derivation can be found in Appendix B, which is available on the first author's website.

${ }^{8}$ Here we resolve any indifference in favor of selling to (the incumbent) Buyer. This tie-breaking assumption is inessential for our results.

9 The first case formally corresponds with the no-contract situation, the second one with the remedy of specific performance. Both these cases are discussed in Section 5.
} 
intermediate case. ${ }^{10}$ Anticipating Seller's breach decision, Buyer then realizes that her investment pays off only when $b=0$. She therefore chooses the efficient investment level $I_{\mathrm{LI}}=I^{*}$. Recall that the efficient investment level is decreasing in the probability of a high outside bid. Because for the equilibrium investment level Seller's equilibrium breach decision is efficient, renegotiations are predicted not to occur.

Under expectation damages (EX) inequality (3) reduces to $0<(1 / 2) \cdot(b-R(I))$. This implies that the equilibrium breach decision is always efficient. For any level of investment chosen renegotiations are therefore predicted not to occur. With expectation damages Buyer's payoff is independent of Seller's breach decision. She obtains her expectancy $R(I)-600$ in either case. It follows immediately that she chooses $I_{\mathrm{EX}}=50$ in equilibrium, irrespective of the value of $p$. Overinvestment under EX is due to the full insurance motive. Buyer is fully protected against separation.

Finally consider the case of reliance damages (RE). Here Buyer is also fully insured against separation. She therefore invests at least 50. But now there is an additional motive to overinvest. To see this, consider Seller's breach decision. Given the relevant range of $I \geq 50$, Seller never breaches when $b=0$. But in case of $b=7000$, Seller breaches whenever $I \leq 85$. He does so either to trade with the outside buyer $(50 \leq I<60)$, or to renegotiate better terms of trade with the original Buyer (i.e. when $I \geq 60$ and thus $R(I) \geq 7000$ ). In the former case Buyer is compensated completely for the investment costs made. She thus obtains a net payoff of zero. In the latter case, besides being reimbursed fully for the costs of investment, Buyer also receives a net profit in the form of an equal share of the surplus up for renegotiation $R(I)-7000$. In principle this gives her an incentive to invest just up to the amount for which Seller is still willing to breach the contract and pay reliance compensation, i.e. $I=85$. Here Buyer overinvests to make separation inefficient. However, Buyer also has to realize that she has to bear the costs of investment when it turns out that $b=0$ and Seller does not breach. This reduces her incentives to invest more than 50 .

Which of the above two effects dominates depends on $p$. When a high outside bid is rather unlikely $(p=(1 / 5))$, it does not pay for Buyer to affect the outcome under this contingency. Here only the insurance motive to overinvest is present and Buyer chooses $I_{\mathrm{RE}}=50$. Renegotiations are then predicted not to occur. But when $p$ is relatively high $(p=(3 / 5))$ it does pay for Buyer to affect the efficient outcome when the outside bid is high. In that case Buyer chooses $I_{\mathrm{RE}}=85,{ }^{11}$ such that Seller surely breaches when $b=7000$. This triggers renegotiation, to arrive at the ex post efficient outcome. In this second case both the insurance and the separation prevention motive are present. Note that under RE equilibrium investment levels are increasing in $p$.

The main equilibrium predictions are summarized in Table 1. Under liquidated damages investment is predicted to be efficient, while under expectation damages and reliance damages overinvestment is predicted to occur. The correlation between $I$ and $p$ can be used to detect the two motives to overinvest. When this correlation is negative, neither the full-insurance nor the breach-prevention motive appears to be effective. In case observed

\footnotetext{
$\overline{10}$ Actually breach is also predicted to occur when $b$ is low and a very high investment level $I$ is chosen; for our parameters $I>70$. Such high investment levels are typically not observed.

11 This equilibrium level follows from allowing multiples of 5 only. In the continuous case the equilibrium reliance level equals 87(1/2) (cf. Appendix B, which is available on the web).
} 
Table 1

Equilibrium predictions

\begin{tabular}{llll}
\hline & LI & EX & RE \\
\hline Investment level $I$ & $I_{\mathrm{LI}}=$ first best & $I_{\mathrm{EX}}>$ first best & $I_{\mathrm{RE}}>$ first best \\
Correlation between $I$ and $p$ & Negative & Zero & Positive \\
Occurrence of renegotiation & None & None & Only in High treatment (for $b=7000)$ \\
Efficiency of renegotiation & Efficient & Efficient & Efficient \\
\hline
\end{tabular}

investment levels are independent of $p$ (only) the full insurance motive appears to be at work. A positive correlation between $I$ and $p$ indicates that both motives to overinvest are operative. Renegotiations are predicted to occur only when it is in the parties' joint interest. On the equilibrium path, i.e. when Buyers' investment choices and Sellers' breach decisions correspond with equilibrium behavior, this implies that they will occur only in the RE-High treatment. And whenever they occur, renegotiations are predicted to yield the efficient outcome without costly delay.

\section{Experimental design}

We ran two sessions per breach remedy. Within a session subjects were confronted with both the Low and the High-treatment. Per session 20 subjects participated, giving 120 subjects in total. They were recruited from the undergraduate student population of the University of Amsterdam. Most of them were students in economics. Subjects received a show up fee of 30,000 experimental points. The conversion rate was one guilder for 2200 points, such that one US dollar corresponded with about 5500 points. Average earnings were USD 19.50 in about two hours.

Each session consisted of 12 periods in which subjects played the four-stage game. These 12 periods were divided into two blocks of six. In one block the value of $p$ was $1 / 5$ (Low-treatment), in the other block $p$ was equal to $3 / 5$ (High-treatment). To control for order effects we conducted for each breach remedy one Low-High session and one HighLow session. Subjects' roles varied over the rounds. Within each treatment each subject was assigned the role of Buyer three times, and the role of Seller also three times. In each period subjects were anonymously (re)matched. Within a treatment they could meet each other only once. Subjects were explicitly informed about this. To enhance comparability the empirical distribution of the outside bid $b$ was exactly the same over the different sessions. We used a distribution that in the aggregate exactly matches the theoretical distribution, but contains sufficient variation over the individual subjects.

The experiment was framed as follows. At the start of each period subjects learned their roles. Then Buyer (subject $\mathrm{A}$ ) had to choose the amount $\mathrm{T}$, a multiple of five between 0 and 100. (T thus reflects investment choice $I$.) The costs of this choice equalled $4 \cdot T^{2}$ and were immediately subtracted from Buyer's account. In the second stage a wheel of fortune determined the value of the outside bid. The wheel had two colors in proportions to the respective probabilities of a low (blue) and a high (yellow) outside bid. When the wheel came to a stop it pointed at a particular color. This color determined the value of the outside bid. In the third stage Seller chose between X (no-breach) and Y (breach). This 
decision of Seller determined the starting point of the renegotiations. The bargaining stage was organized as described in Section 2.1.

The experiment was computerized. Subjects started with on-screen instructions. Before the experiment started subjects had to answer a number of questions correctly. Subjects also received a summary of the instructions on paper. ${ }^{12}$ The instructions were phrased neutrally. In particular, words like opponent, game, investment, buyer or seller were not used. Before the play of the 12 periods one practice period was played. At the end of the experiment subjects filled out a short questionnaire and the earned experimental points were converted to money. Subjects were paid individually and discreetly.

We made a large effort to present the procedures to the subjects in a very clear and accessible way. The instructions explained carefully how the combination of Buyer's choice of $T$ in stage 1, Nature's draw of $b$ in stage 2 and Seller's breach decision in stage 3 together determined the threat points and the renegotiation surplus for stage 4. After each decision/draw, the consequences were made explicit. In particular, before the buyer's investment choice the subjects had on their screens a table which expresses payoffs as functions of $T, b$ (the color of the wheel) and Seller's breach options ( $X$ or $Y$ ). After the buyer made her investment choice, the actually chosen value of $T$ replaced the symbol $T$. Before the wheel of fortune turned, the table contained amounts in yellow and blue. When the wheel stopped at e.g. yellow, the amounts in yellow remained yellow, while those in blue became grey because they were no longer relevant. Similarly, after Seller's choice between $X$ and $Y$ the numbers belonging to the option that was not chosen became grey. In this way, subjects received the information about decisions and draws made in the previous stages and their consequences in a clear-cut and concise way. Appendix A contains examples of the computer screens described here.

\section{Results}

\subsection{Reliance levels}

Our first result concerns the relationship between reliance levels and the probability of a high outside bid.

Result 1. Under LI reliance levels are decreasing in $p$, while under EX they remain virtually constant. Under RE reliance levels increase when $p$ increases.

Evidence for Result 1 is provided in Table 2, which reports average investment levels by treatment. (Ignore the columns labeled "optimum" for the moment.) Recall that each subject in the experiment makes six investment decisions: three decisions in the Lowtreatment and three decisions in the High-treatment. For each subject we calculated the mean investment levels in these two treatments. We report the results of statistical tests

\footnotetext{
12 A translation of this summary sheet can be downloaded from the first author's website: http://www1.fee.uva.nl/pp/rsloof/.
} 
based on these average investment levels of individual investors. ${ }^{13}$ Wilcoxon signrank tests are used to test for differences within a row (last column in upper part) and Mann-Whitney ranksum tests for differences within a column (see the lower part of Table 2). We always use (the more conservative) two-sided tests.

Result 1 relates to the within-remedy comparisons. In line with theoretical predictions investment levels are decreasing in $p$ under liquidated damages. Under EX we observe a $5 \%$ decrease in case $p$ increases. While statistically significant, economically the size of this effect can be viewed as modest. We therefore conclude that under EX investment levels remain virtually constant. Under RE investment levels are increasing in $p$, as predicted. ${ }^{14}$

The next result relates to the absolute reliance levels and to a comparison across the different damage payments.

Result 2. (i) In both the Low and the High-treatment reliance levels are significantly higher under EX and RE than under LI. (ii) Reliance levels are also significantly higher under RE than under EX. (iii) Under all three remedies overinvestment occurs.

Evidence for the first two parts of Result 2 is provided in the lower part of Table 2. Ranksum tests reveal that the between-remedy differences in reliance levels are in all cases significant. Except for EX-Low versus RE-Low, the significant differences found are in line with the theoretical predictions. ${ }^{15}$ Specifically, under LI reliance levels are lower than under EX and RE, and reliance levels are higher in the RE-High treatment than in EX-High.

The third part of Result 2 follows from a comparison of the average reliance levels with the predicted levels. Taking all investment decisions into account, it turns out that in two of the six treatments average reliance levels deviate substantially from the theoretical predictions. For LI-High the actual investment level exceeds the predicted level by more than $50 \%$. For

\footnotetext{
13 These tests are based on pooled sessions. Using Mann-Whitney ranksum tests, in five out of six treatments we found no differences at the $5 \%$ level in investment rates between the two sessions that were held for each of the treatments. (These tests are based on the mean reliance levels per $p$-level of each subject.) The single exception concerns the EX-High treatment. Here reliance levels in one session were significantly higher than in the other session $(51.75>46.75, p=0.003)$. This points at an order effect; the higher investment levels are observed for the Low-High order. Yet for the other five treatments order effects are absent. Pooling over the sessions does not affect our conclusions. When we consider the two EX sessions in isolation, we observe that in one of them reliance levels are significantly decreasing in the probability of a high outside bid $(p=0.02)$, but in the other session this is not the case. There reliance levels under the EX-Low and EX-high treatment are not significantly different from each other $(p=0.48)$. This supports the conclusion drawn in Result 1 .

${ }^{14}$ In the experiment we used a rotating scheme that divides the 20 subjects within a session into two groups that were independently matched. Members of one group were never matched with members of the other group. This gives for each remedy four independent "group-level" observations. Using groups rather than subjects as the independent unit of observation allows for an alternative test. With four matched pairs of observations per remedy, the smallest possible significance level that a two-tailed signrank test can attain equals 0.125 . For LI and RE we find exactly this level. For EX the $p$-value obtained from the group-level comparison equals 0.375 . The latter finding provides an additional justification for using the term 'virtually' in Result 1.

15 For the situation without renegotiation Sloof et al. (2003) also found that reliance expenditures under RE-Low are significantly larger than under EX-Low (whereas theory predicts them to be equal). However, using group level data rather than individual level data leads to an insignificant $p$-value of $p=0.1572$ (the smallest significance level of a ranksum test with $m=n=4$ groups equals 0.0286 ).
} 
Table 2

Mean investment levels by treatment and tests for equality

\begin{tabular}{|c|c|c|c|c|c|c|c|}
\hline \multirow[t]{2}{*}{ Damages } & \multicolumn{3}{|c|}{ Low: $p=(1 / 5)$; efficient: 40} & \multicolumn{3}{|c|}{ High: $p=(3 / 5)$; efficient: 20} & \multirow{2}{*}{$\begin{array}{l}\text { Signrank tests ( } p \text {-values) } \\
\text { Low vs. High }\end{array}$} \\
\hline & Predicted & Actual & "Optimum" & Predicted & Actual & "Optimum" & \\
\hline LI & 40 & $46.71(12.96)$ & $33.40(3.16)$ & 20 & $32.21(15.80)$ & $19.10(5.97)$ & 0.0002 \\
\hline \multirow[t]{2}{*}{$\mathrm{RE}$} & 50 & $58.08(12.38)$ & $56.24(4.46)$ & 85 & $68.88(13.23)$ & . & 0.0004 \\
\hline & & $\begin{array}{l}\text { Ranksum tests } \\
\text { (p-values) }\end{array}$ & & & $\begin{array}{l}\text { Ranksum tests } \\
\text { ( } p \text {-values) }\end{array}$ & & \\
\hline LI vs. RE & & 0.0002 & & & 0.0000 & & \\
\hline EX vs. RE & & 0.0243 & & & 0.0000 & & \\
\hline
\end{tabular}

Remark: For each comparison $p$-values are based on the mean investment levels of individual investors. The signrank tests are based on 40 matched pairs (i.e. 40 investors), the Ranksum tests have $m=n=40$ observations per remedy. Tests are two-sided, standard deviations appear in parentheses. 
RE-High the average investment level is substantially below the predicted level. ${ }^{16}$ In the other four treatments the mean reliance levels are fairly close to the predicted levels. When we only consider subjects' last investment decisions (out of a total of three per treatment), we observe that these are not significantly different from the means of all investment decisions in four of the six treatments (Wilcoxon signrank tests on individual mean investment rates, $5 \%$ level). The two exceptions are exactly LI-High and RE-High. Here significant learning effects are found. In both treatments the adjustment is in the direction of the predicted investment levels. For LI-High the mean investment level decreases (to 25.75 on average) and for RE-High it increases (to 74.63 on average). Hence, experienced subjects choose investment levels which are fairly close to the predicted levels.

Together Results 1 and 2 provide strong evidence that both motives for overinvestment are at work. First, the operation of the full insurance motive is supported by the different correlations between investment levels and $p$ for EX and LI respectively (cf. Result 1). It also follows from the across remedies comparison between EX (and RE) and LI reported in Result 2. Second, the difference between the comparative statics results for RE and EX (Result 1) and the significant difference between observed investment levels under RE-High and EX-High (Result 2) both point at the presence of the separation prevention motive. ${ }^{17}$ In the no-renegotiation setup of Sloof et al. (2003) the same comparative statics results were obtained. The two experiments together thus provide ample evidence for the relevance of the two overinvestment motives distinguished in the theoretical literature.

For liquidated damages Result 2(iii) differs from the findings in Sloof et al. (2003); in the absence of renegotiations average reliance expenditures under LI were very close to the efficient levels. In contrast, here on average overinvestment is observed. ${ }^{18}$ Hence, when renegotiations are allowed for (as they typically are in practice), appropriately designed liquidated damages may be less attractive than the earlier findings for the no-renegotiation case suggests. In Section 6 we will consider which remedy performs best from an efficiency perspective.

\subsection{Renegotiations}

Theory predicts that renegotiations occur only when it is efficient to do so. This implies that, given equilibrium investment and breach behavior, they do not occur under LI, EX and RE-Low, but do occur under RE-High. Our next result relates to this.

\footnotetext{
$\overline{16}$ But note that it is still well above the level observed under RE-Low to justify a positive correlation with $p$ (cf. Result 1).

17 Note that the fact that we also find that investment levels are higher under RE-Low than under EX-Low does not invalidate this conclusion. The separation prevention motive predicts that the difference between investment levels under RE-High and RE-Low is significantly larger than the difference between those under EX-High and EX-Low. With the former difference significantly positive and the latter difference weakly negative, this indeed applies.

${ }^{18}$ Comparing the renegotiation situation with the no-renegotiation case, we find that reliance levels differ significantly (at the 5\% level) for LI-Low, but not for LI-High. This holds after controlling for the learning effects observed when renegotiation is allowed.
} 
Table 3

Occurrence of renegotiations

\begin{tabular}{|c|c|c|c|c|c|c|c|c|}
\hline & \multicolumn{3}{|c|}{ Inefficient outcome } & \multirow{3}{*}{$\begin{array}{l}b=R(I) \\
\text { (4) }\end{array}$} & \multicolumn{3}{|c|}{ Efficient outcome } & \multirow{3}{*}{$\begin{array}{l}n \\
\\
(8)\end{array}$} \\
\hline & \multicolumn{2}{|c|}{ Renegotiation } & \multirow{2}{*}{$\begin{array}{l}\text { No-ren. } \\
\text { (3) }\end{array}$} & & \multicolumn{2}{|c|}{ Renegotiation } & \multirow{2}{*}{$\begin{array}{l}\text { No-ren. }^{*} \\
\text { (7) }\end{array}$} & \\
\hline & $\begin{array}{l}\text { Agree* } \\
\text { (1) }\end{array}$ & $\begin{array}{l}\text { Disagree } \\
(2)\end{array}$ & & & $\begin{array}{l}\text { Agree } \\
(5)\end{array}$ & $\begin{array}{l}\text { Disagree* } \\
(6)\end{array}$ & & \\
\hline LI-Low & $16(10)$ & $5(3)$ & $5(4)$ & $1(0)$ & $0(0)$ & $7(0)$ & $86(1)$ & 120 \\
\hline LI-High & $20(12)$ & $0(0)$ & $5(4)$ & $2(0)$ & $0(0)$ & $4(0)$ & $89(2)$ & 120 \\
\hline EX-Low & $1(1)$ & $0(0)$ & $6(6)$ & $0(0)$ & $0(0)$ & $6(0)$ & $107(0)$ & 120 \\
\hline EX-High & $7(7)$ & $1(1)$ & $5(5)$ & $6(0)$ & $2(0)$ & $7(0)$ & $92(0)$ & 120 \\
\hline RE-Low & $43(31)$ & $1(0)$ & $0(0)$ & $1(0)$ & $1(0)$ & $4(0)$ & $70(5)$ & 120 \\
\hline RE-High & $36(7)$ & $6(2)$ & $7(2)$ & $6(0)$ & $1(0)$ & $1(0)$ & $63(5)$ & 120 \\
\hline
\end{tabular}

Remark: The left (right) hand part of the table concerns cases where Seller's breach decision results in an inefficient (efficient) outcome. Equilibrium predictions are marked with an *. Within parentheses appear the number of nonequilibrium breach decisions.

Result 3. Actual renegotiations almost never $(<1 \%)$ occur when it is inefficient to do so. In case it is efficient to renegotiate, actual renegotiations take place in about $83 \%$ of the cases. Under EX actual renegotiations are almost absent, while under LI and RE they occur quite often.

Table 3 presents for each treatment the overall outcome of the renegotiation stage. The left hand part of the table considers situations in which renegotiations are predicted to take place. Here the breach decision of Seller would by itself result in an inefficient outcome. The right hand part concerns cases where Seller's breach decision is efficient. Then renegotiations are not needed to arrive at the efficient outcome. (When $b=R(I)$ both trade and separation are efficient.) The columns labeled 'agree' report the number of observations in which the parties arrived at an agreement during the renegotiations. Under 'disagree' we report the number of renegotiations that ended in disagreement. The columns labeled 'no-ren.' list the number of instances in which at least one of the subjects within a pair did not want to renegotiate.

Apart from simply refusing to do so, in the experiment there is a second way to reveal an unwillingness to renegotiate efficient outcomes. Subjects could always demand at least their threat point. When Seller's breach decision is efficient, such that the surplus up for renegotiation falls short of the sum of the two threat points, such a strategy would lead to disagreement. For this reason we interpret renegotiations of efficient outcomes that end in disagreement as indicative of an unwillingness to renegotiate (column (6) in Table 3). The remaining renegotiations that take place are referred to as actual renegotiations in Result 3. These are the numbers reported in the columns (1), (2) and (5). We then observe that actual renegotiations of efficient outcomes (column (5)) take place in only 4 out of 540 cases.

The picture is markedly different when it is efficient to renegotiate. Then actual renegotiations take place in overall 136 out of 164 cases (83\%). These cases mainly belong to the LI and RE remedies. Yet there seems to be no systematic pattern over the Low and High treatments.

Overall we conclude that the occurrence of renegotiations conditional on the actual investment and breach decisions is well in line with theoretical predictions. Renegotiations 
typically take place when there are efficiency gains to be made ex post. At the same time we observe that under LI and RE-Low renegotiations of inefficient outcomes occur considerably more often than predicted. The explanation for this lies in investment and/or breach decisions that deviate from the equilibrium predictions.

Under expectation damages renegotiations of inefficient outcomes are rather infrequent. But when they occur, they can be attributed completely to dis-equilibrium breach behavior. This holds because under expectation damages the breach decision is predicted to be efficient, irrespective of the reliance level chosen. An inefficient outcome after the breach decision stage is thus necessarily a consequence of a non-equilibrium breach decision. Under LI and RE-Low the situation is more complicated. There inefficient outcomes can be caused by either non-equilibrium investment levels or non-equilibrium breach decisions. ${ }^{19}$ The numbers within parentheses in Table 3 report the latter. Overall for LI and RE-Low we observe that around 66\% (56 out of 85) of the actual renegotiations of inefficient outcomes are caused by non-equilibrium breach decisions.

Only under RE-High renegotiations of inefficient outcomes are actually predicted to occur. In particular, given $I_{\mathrm{RE}}^{*}=85$ they should occur when $b=7000$. Theoretically we thus should expect $(3 / 5) \cdot 120=72$ renegotiations of inefficient outcomes. The observed number of 42 is much lower. Moreover, nine of these can be attributed to non-equilibrium breach decisions. Only the remaining 33 observations can be attributed to Buyer trying to prevent separation through overinvestment. Hence, compared to the theoretical prediction Buyer invests too little. A possible explanation for this could be that Buyer's gains from the renegotiations are smaller than predicted. The next result relates to this issue.

Result 4. First and accepted offers under LI, EX and RE give Buyer on average a share above the equal split and below the theoretically predicted 'split-the-difference' solution. Under LI and RE first offers and finally accepted offers differ in the return on investment and in the remuneration of investment costs.

Table 4 reports the outcome of the renegotiations after an inefficient breach decision. Per treatment we separately report characteristics of first offers and of accepted offers. While theory predicts that first offers are immediately accepted, in practice this is not always the case. Column (1) reports the average equilibrium prediction for Buyer's share given actual investment; the 'split-the-difference' solution. The next column reports her average actual share and column (3) the average equal split outcome. Also the average number of bargaining rounds until agreement is reported, together with the number of observations on which the averages are based. In all treatments accepted offers lie in between the equal split and the 'split-the-difference' solution. On average Buyers thus earn less in the renegotiations than predicted. This supports the first part of Result 4.

For investment incentives the marginal return on investment is important. Under LI only 6 of the 41 renegotiations reported in Table 4 take place after an inefficient decision not to breach. In all these cases Seller decided not to breach, although separation is efficient (i.e.

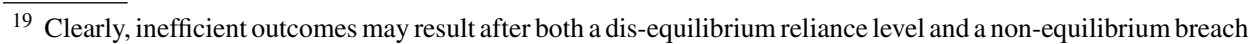
decision. In that case, like under expectation damages, we attribute the inefficient outcome to the non-equilibrium breach decision.
} 
Table 4

Outcome of renegotiations of inefficient outcomes

\begin{tabular}{|c|c|c|c|c|c|c|}
\hline & & \multicolumn{3}{|c|}{ Buyer's average share } & \multirow{2}{*}{$\begin{array}{l}\text { \# of rounds } \\
\text { (4) }\end{array}$} & \multirow{2}{*}{$\begin{array}{l}n \\
(5) \\
\end{array}$} \\
\hline & & $\begin{array}{l}\text { Predicted } \\
\text { (1) }\end{array}$ & $\begin{array}{l}\text { Actual } \\
(2)\end{array}$ & $\begin{array}{l}\text { Equal split } \\
\text { (3) }\end{array}$ & & \\
\hline \multirow[t]{2}{*}{ LI-Low } & First & 6460 & 4274 & 3560 & . & 21 \\
\hline & Accepted & 6447 & 5519 & 3484 & 2.31 & 16 \\
\hline \multirow[t]{2}{*}{ LI-High } & First & 5050 & 2825 & 3338 & . & 20 \\
\hline & Accepted & 5050 & 4588 & 3338 & 2.25 & 20 \\
\hline \multirow[t]{2}{*}{ EX-Low } & First & 8400 & 5000 & 3000 & . & 1 \\
\hline & Accepted & 8400 & 5500 & 3000 & 2 & 1 \\
\hline \multirow[t]{2}{*}{ EX-High } & First & 6213 & 3775 & 3438 & . & 8 \\
\hline & Accepted & 6257 & 5843 & 3429 & 1.86 & 7 \\
\hline \multirow{2}{*}{ RE-Low } & First & 6579 & 4964 & 3358 & . & 44 \\
\hline & Accepted & 6637 & 5567 & 3378 & 2 & 43 \\
\hline \multirow[t]{2}{*}{ RE-High } & First & 7197 & 6282 & 4185 & . & 42 \\
\hline & Accepted & 6915 & 6716 & 4097 & 1.69 & 36 \\
\hline
\end{tabular}

Remark: \# of rounds gives the average number of bargaining rounds. $n$ denotes the number of observations.

$b=7000$ and $I<60$ ). The remaining 35 observations concern inefficient breaches; Seller decided to breach, while trade between the original parties is efficient (either because $b=0$, or $b=7000$ and $I \geq 60$ ). This also applies for all 86 renegotiations observed under RE. We therefore concentrate on renegotiations that follow after an inefficient breach. For these cases, Table 5 present results from regressing first offers and final agreements on the value of the outside bid, the investment level, the squared investment level (i.e. investment costs) and a period trend. The latter is included to correct the estimates for possible experience effects.

In the column for first offers under liquidated damages, we observe that the return Seller offers to Buyer for her investment is not significantly different from the predicted return of 50. In his first offer Seller also treats investment costs as sunk and does not

Table 5

Regressions explaining first/accepted offers after inefficient breach

\begin{tabular}{|c|c|c|c|c|c|c|}
\hline & \multicolumn{3}{|l|}{ LI } & \multicolumn{3}{|l|}{$\mathrm{RE}$} \\
\hline & Pred. & First offer & Accepted & Pred. & First offer & Accepted \\
\hline Const. & 3900 & $-760(1689)$ & $3915(893)^{* * *}$ & 500 & $-224(903)$ & $556(729)$ \\
\hline$b$ & -.5 & $-.314(.106)^{* * *}$ & $-.452(.055)^{* * *}$ & -.5 & $-.091(.051)^{*}$ & $-.250(.042)^{* * *}$ \\
\hline$I$ & 50 & $78.0(56.8)$ & $-39.9(30.65)$ & 50 & $65.6(32.3)^{* *}$ & $34.3(26.3)$ \\
\hline$I^{2}$ & 0 & $.034(.464)$ & $.987(.253)^{* * *}$ & 1 & $.284(.300)$ & $.815(.248)^{* * *}$ \\
\hline$t$ & 0 & $91.2(88.3)$ & $105(44.5)^{* *}$ & 0 & $77.0(40.3)^{*}$ & $59.4(33.2)^{*}$ \\
\hline$n$ & 45 & 35 & 30 & 93 & 86 & 79 \\
\hline Adj. $R^{2}$ & & .46 & .81 & & .67 & .81 \\
\hline
\end{tabular}

Remark: Regressions explaining Buyer's share. Standard deviations within parentheses. Significant coefficients at $1 \% / 5 \% / 10 \%$ level are marked with $* * * / * * / *$. 
remunerate these. ${ }^{20}$ This follows because the coefficient for $I^{2}$ appears to be insignificant, as is theoretically predicted. Comparing these results with those for finally accepted offers we notice that the return on investment has gone down, while the remuneration of investment costs has increased. A similar pattern emerges for first offers and accepted offers under reliance damages, see the right hand part of Table 5. This gives the second part of Result 5 .

The observed differences between first offers and accepted offers suggest a conflict between Buyer and Seller about the elements that should determine their payments. ${ }^{21} \mathrm{On}$ the one hand, Buyer may self-servingly expect to be compensated for the costs of investment. On the other hand, Seller may self-servingly believe that he is entitled to a large share because he was unlucky with the draw of a low alternative trading opportunity (i.e. $b=0$ ) or because he makes the first offer. Previous experiments have already shown that such self-serving biases may result in bargaining impasse and costly delay (cf. Babcock \& Loewenstein, 1997, Camerer, 2003). Moreover, they may affect investment incentives and induce parties to invest more than is individually rational (cf. Sloof, Sonnemans, \& Oosterbeek, 2004). It should be noted, however, that while the results are consistent with self-serving biases, they do not prove that such biases are indeed the driving forces, as we have no direct evidence on this.

For liquidated damages it follows from Table 5 that, when it comes to renegotiations, Buyer gets a lower marginal return on investment than predicted. Yet the actual investment levels chosen under LI exceed the predicted ones (cf. Table 2). This suggests that Buyer may overinvest not only from a social, but also from a selfish point of view. To examine this more thoroughly, we ran regressions with Buyer's net payoff as dependent variable, and investment and investment squared as independent variables. We also included a time trend. The investment levels that are optimal from a selfish point of view (along with their standard errors) can be calculated from the estimation results and are reported in Table 2. In the RE-High treatment the variance in actual bargaining outcomes was too large to obtain sensible estimation results. ${ }^{22}$

Two comparisions of interest can be made. First, when we compare the "optimum" investment levels with the predicted ones, we observe that they are not that different. It is indeed optimal to invest more under EX and RE than under LI, as is predicted. Also in line with theoretical predictions, the correlation between optimum investment levels and $p$ is negative under LI and zero under EX. It thus appears that actual breach and renegotiation behavior indeed provides the two predicted motives to overinvest. Second, the calculated optimum investment levels are close to the actual investment levels for RE-Low, EX-Low and EX-High. For the LI-treatments actual levels exceed the optimum levels. Here Buyer overinvests from a selfish point of view. A potential explanation for this is the self-serving bias mentioned above.

Overall we conclude that the actual breach and renegotiation outcomes indeed provide the two theoretically predicted motives to overinvest under EX and RE. Apart from that, a

\footnotetext{
${ }^{20}$ At the same time, however, Seller offers Buyer a smaller fixed payment than predicted; theory predicts a fixed payment of $3900-.5 \cdot b$, i.e. 3900 for $b=0$ and 400 for $b=7000$.

${ }^{21}$ Note in this regard also that average first offers are substantially below finally agreed shares (cf. Table 4).

22 In the regression of net payoffs the coefficients of both $I$ and $I^{2}$ were insignificant and the adjusted $R^{2}$ equalled 01 .
} 
self-serving bias seems to lead Buyers to anticipate the outcome of the renegotiation stage incorrectly. This provides an explanation why Buyers also overinvest under appropriately designed liquidated damages (albeit to a much smaller extent).

\section{Reliance without sophisticated remedies}

\subsection{Basic setup, predictions and design}

\subsubsection{Basic setup}

The results reported in the previous section reveal that sophisticated breach remedies cause overreliance, as is theoretically predicted (except for LI). We next turn to the question whether they are actually needed for protection against holdup. In order to answer this we investigate situations where sophisticated breach remedies are absent. We consider two extreme (degenerate) forms of breach remedies. The first one is specific performance (SP). As noted in the Introduction, specific performance corresponds to a "property rule" common in civil law systems. Under this remedy Seller is obliged to sell his unit to Buyer if she requires him to do so. This amounts to a situation in which the breach payment is infinitely high; $\delta_{\mathrm{SP}}(I)=\infty$. The second one is the situation without an initial contract (NC). Then there is simply no contract that can be breached and Seller is free to go. This corresponds to the situation of $\delta_{\mathrm{NC}}(I)=0$ and $f=0$ in the setup of Section 2.1.

Naturally, in both cases breach decision stage 3 is obsolete. Under NC there is no initial contract that can be breached. After the outside bid becomes known Buyer and Seller simply negotiate about the terms of (possible) trade. In these negotiations the threat point of Seller equals his outside bid, while the threat point of Buyer equals zero. ${ }^{23}$ In case of SP there exists a contract which parties agreed upon in stage 0 , but unilateral breach of this contract is forbidden. Parties have the opportunity to renegotiate this contract in stage 4 . They may jointly decide to separate at a different damage payment. ${ }^{24}$

\subsubsection{Equilibrium predictions}

Actual (re)negotiations take place only when mutual gains from doing so can be obtained. In the absence of a contract this implies that trade between Buyer and Seller must be efficient $(R(I) \geq b)$. In that case Buyer is predicted to get a share equal to $(1 / 2)(R(I)-b)$, while Seller obtains the remainder. Note that in the negotiations Seller can "hold up" Buyer, such that she captures only $50 \%$ of the marginal return on investment. Anticipating this, Buyer chooses an investment level that is only $50 \%$ of the efficient level: $I_{\mathrm{NC}}=(1 / 2) I^{*}{ }^{25}$ Given the equilibrium investment levels negotiations take place only when $b=0$. Table 6 summarizes these predictions.

\footnotetext{
${ }^{23}$ In the notation of Section 2.1: $R S=R(I), T P_{\mathrm{B}}=0$ and $T P_{\mathrm{S}}=b$ (and $f=0$ ).

${ }^{24}$ Here we have: $R S=b, T P_{\mathrm{B}}=R(I)-f$ and $T P_{\mathrm{S}}=f=600$.

25 As shown by Segal and Whinston (2000) holdup in this case cannot be solved by an exclusivity provision. Under such a provision Seller is restricted to sell his unit to Buyer only (but he is not required to do so). In our setup Buyer then obtains $(1 / 2) \cdot \max \{R(I), b\}=(1 / 2) \cdot \max \{R(I)-b, 0\}+(1 / 2) b$ in the renegotiations. This is simply $(1 / 2) b$ on top of what she receives in the no contract case, and therefore investment incentives are not affected.
} 
Table 6

Equilibrium predictions

\begin{tabular}{lll}
\hline & $\mathrm{NC}$ & $\mathrm{SP}$ \\
\hline Investment level $I$ & $I_{\mathrm{NC}}<$ first best & $I_{\mathrm{SP}}>$ first best \\
Correlation between $I$ and $p$ & Negative & Negative \\
Occurrence of renegotiation & Only if $b=0$ & Only if $b=7000$ \\
Efficiency of renegotiation & Efficient & Efficient \\
\hline
\end{tabular}

Under specific performance Buyer can always claim trade at a price of $f=600$. Renegotiations therefore will only take place when trade between the original trading partners appears to be inefficient $(R(I)<b)$. In that case Buyer obtains $(R(I)-f)+(1 / 2)(b-R(I))$, where the second term equals the gain from renegotiations. Note that when the investment appears socially unprofitable (i.e. when $b=7000>R(I)$ ), Buyer still receives half of the (private) return on investment. In that sense Buyer is partially - for $50 \%$ - insured against separation. Under full insurance the equilibrium investment level is 50, while in the absence of insurance it equals the efficient level $I^{*}$. Under $50 \%$-insurance the equilibrium investment level then just equals the average: $I_{\mathrm{SP}}=(1 / 2)\left(50+I^{*}\right)$. This yields predicted investment levels of 45 in the Low-treatment and 35 in the High-treatment. Hence, just like the sophisticated remedies based on a "liability rule", also the SP breach remedy is predicted to cause overreliance. The driving force is the partial insurance of Buyer against separation.

It may be instructive to point out here that the remedy of specific performance differs from a so-called "exclusivity provision". Under such a provision Seller is restricted to sell his unit to Buyer only, but in contrast to SP he is not required to do so. As shown by Segal and Whinston (2000), an exclusivity provision does not protect specific investments against holdup. In particular, under an exclusivity provision Buyer obtains $(1 / 2) \cdot \max \{R(I), b\}=$ $(1 / 2) \cdot \max \{R(I)-b, 0\}+(1 / 2) b$ in the renegotiations. This is simply $(1 / 2) b$ on top of what she receives in the no contract case, and therefore (theoretically) investment incentives are unaffected.

\subsubsection{Experimental design}

We ran two sessions for the NC-game and two sessions for the SP-game. As before, in each session subjects were confronted with both the low and the high level of $p$. Per session 20 subjects participated, so that 80 new subjects participated in four sessions. Parameter choices were exactly the same as before. Subjects earned on average USD 21 in two hours.

The additional sessions resembled the previous ones for the sophisticated breach remedies as closely as possible. The only difference was that the game played in each period was now framed as a three-stage game. Breach decision stage 3 was dropped and the renegotiation stage was labeled as being the third stage. Thus, after the wheel of fortune came to a stop subjects immediately turned to the renegotiation stage. In the computer screens (cf. Appendix A) there were only two instead of four columns in the upper table. 


\subsection{Results}

\subsubsection{Reliance levels}

The main finding concerning investment levels is summarized in Result 5.

Result 5. (i) In case of NC underinvestment is observed in the Low-treatment, but not in the High-treatment. (ii) SP always leads to overinvestment. (iii) Under NC investment levels are decreasing in $p$, while under SP they remain virtually constant when $p$ changes.

Evidence for Result 5 is provided in Table 7. As before statistical tests are based on individual mean investment levels. There appears to be no holdup problem when the probability of a high outside bid is high. In the absence of a contract Buyer chooses the first best investment level on average. In the Low-treatment holdup does occur, but is less severe than predicted. Under SP Buyer invests significantly more than under NC. Substantial overinvestment occurs mainly in the High-treatment, as predicted.

Comparing the actual reliance levels for Low and High, Table 7 shows that investment levels are decreasing in $p$ under NC. In case of SP the data reveal no significant differences at the 5\% level between the Low and the High-treatment. This indicates the presence of the insurance motive. In contrast to theoretical predictions, however, insurance appears to be complete rather than partial. ${ }^{26}$

The correlation between $I$ and $p$ - i.e. the comparison between the Low and the Hightreatment - enables us to identify the two motives to overinvest (cf. Tables 1 and 6). From a more practical point of view the Low-treatment seems more realistic though. In reality parties will typically select trading partners with whom they believe trade is likely to be efficient. For the Low-treatment we then observe that, without a contract, there will be underinvestment. The various breach remedies appear to overcome this holdup problem; for all of them investment levels are significantly higher than under no contract (see the lower part in Table 7). Breach remedies thus indeed serve the useful purpose of protecting specific investments. All the remedies considered, however, induce overreliance. Simply comparing the average investment levels reported in Tables 2 and 7 suggests that liquidated damages are best, as they induce the least overinvestment. In the Low-treatment differences between LI and SP are not significant though. This results from the fact that there is much more variation in investment levels under LI than under SP (see the standard deviations reported in the tables). Moreover, the comparison of investment levels does not take possible inefficiencies at the renegotiation stage into account. In Section 6 we return to this when we compare all the cases considered on efficiency grounds.

\subsubsection{Renegotiations}

The first result in this subsection concerns the occurrence of actual renegotiations. As before, actual renegotiations refer to the cases where parties display a clear willingness to renegotiate.

\footnotetext{
26 The difference between SP-Low and SP-High is almost significant at the 5\% level. Yet economically the difference is modest; only a $7 \%$ decrease is observed, while a decrease of $22 \%$ is predicted. This explains why we use the term 'virtually' in Result 5(iii).
} 
Table 7

Mean investment levels by treatment and tests for equality

\begin{tabular}{|c|c|c|c|c|c|c|c|}
\hline \multirow[b]{2}{*}{ Damages } & \multicolumn{3}{|c|}{ Low: $p=(1 / 5)$; efficient: 40} & \multicolumn{3}{|c|}{ High: $p=(3 / 5)$; efficient: 20} & \multirow{2}{*}{$\begin{array}{l}\text { Signrank tests } \\
\text { ( } p \text {-values) Low vs. } \\
\text { High }\end{array}$} \\
\hline & Predicted & Actual & "Optimum" & Predicted & Actual & "Optimum" & \\
\hline $\mathrm{NC}$ & 20 & $28.83(12.34)$ & $12.00(7.80)$ & 10 & $21.88(13.07)$ & $3.44(7.30)$ & 0.0010 \\
\hline \multirow[t]{2}{*}{ SP } & 45 & $49.88(3.89)$ & $47.54(2.39)$ & 35 & $46.63(9.87)$ & $35.93(2.90)$ & 0.0546 \\
\hline & & Ranksum tests & & & $\begin{array}{l}\text { Ranksum test } \\
\text { ( } p \text {-values) }\end{array}$ & & \\
\hline NC vs. SP, LI, EX, RE & & 0.0000 & & & 0.0000 & & \\
\hline SP vs. LI & & 0.0988 & & & 0.0000 & & \\
\hline SP vs. EX & & 0.1119 & & & 0.1237 & & \\
\hline SP vs. RE & & 0.0004 & & & 0.0000 & & \\
\hline
\end{tabular}

Remark: For each comparison $p$-values are based on the mean investment levels of individual investors. The signrank tests are based on 40 matched pairs (i.e. 40 investors), the Ranksum tests have $m=n=40$ observations per remedy. Tests are two-sided, standard deviations appear in parentheses. 
Table 8

Occurrence of renegotiations

\begin{tabular}{|c|c|c|c|c|c|c|c|c|}
\hline & \multicolumn{3}{|c|}{ Inefficient outcome } & \multirow{3}{*}{$\begin{array}{l}b=R(I) \\
\text { (4) }\end{array}$} & \multicolumn{3}{|c|}{ Efficient outcome } & \multirow{3}{*}{$\begin{array}{l}n \\
\\
(8)\end{array}$} \\
\hline & \multicolumn{2}{|c|}{ Renegotiation } & \multirow{2}{*}{$\begin{array}{l}\text { No-ren. } \\
\text { (3) }\end{array}$} & & \multicolumn{2}{|c|}{ Renegotiation } & \multirow{2}{*}{$\begin{array}{l}\text { No-ren. }^{*} \\
\text { (7) }\end{array}$} & \\
\hline & $\begin{array}{l}\text { Agree* } \\
\text { (1) }\end{array}$ & $\begin{array}{l}\text { Disagree } \\
\text { (2) }\end{array}$ & & & $\begin{array}{l}\text { Agree } \\
(5)\end{array}$ & $\begin{array}{l}\text { Disagree* } \\
(6)\end{array}$ & & \\
\hline NC-Low & 85 & 8 & 3 & 2 & 3 & 0 & 19 & 120 \\
\hline NC-High & $41(1)$ & 1 & 7 & 2 & 8 & 1 & 60 & 120 \\
\hline SP-Low & 16 & 1 & 6 & 0 & 1 & 19 & $77(1)$ & 120 \\
\hline SP-High & 55 & 5 & 10 & 1 & 0 & 7 & $42(1)$ & 120 \\
\hline
\end{tabular}

Remark: The left (right) hand part of the table concerns cases where the outcome before stage 4 is inefficient (efficient). Equilibrium predictions are marked with an $*$. Within parentheses appear the number of observations with $b=7000$ and $I>60$.

Result 6. Under NC actual renegotiations occur in around $12 \%$ of the cases when it is inefficient to do so. Under SP this is almost never the case $(<1 \%)$. When it is efficient to renegotiate, actual renegotiations take place in $89 \%$ of the cases. Under NC they occur mostly after $b=0$, but also occur when $b=7000$. Under SP they only occur after $b=7000$.

Table 8 presents the overall outcomes of the renegotiation stage. It has a similar setup as Table 3. Under NC the status quo outcome is no-trade, while under SP it equals trade. The left (right) hand part of the table considers situations in which the status quo outcome turns out to be inefficient (efficient), given the actual outside bid and the investment level chosen. Theory predicts that actual renegotiations occur only when the status quo is inefficient. Table 8 reveals that actual renegotiations of inefficient outcomes (columns (1) and (2)) take place in overall 212 out of 238 cases (89\%). Actual renegotiations of efficient outcomes (column (5)) are essentially absent under SP, but in the absence of a contract occur in 11 out of 91 cases $(12 \%)$.

Without a contract the status quo outcome equals no-trade. This is necessarily inefficient when $b=0$, given $R(I)>0$. No-trade is also inefficient when $b=7000$ and $I>60$. Theory predicts that $I_{\mathrm{NC}}<60$, and thus that the latter situation does not occur. Table 8 reveals that this is indeed the case; instances with $b=7000$ and $I>60$ are almost absent under NC, see the number in parentheses. Hence, actual renegotiations of inefficient outcomes (almost) only follow after $b=0$. Actual renegotiations of efficient outcomes occur after $b=7000$ only.

In case of specific performance the status quo outcome equals trade. Trade is inefficient only when $b=7000$ and $I<60$. Theory predicts that $I_{\mathrm{SP}}<60$, and thus that an inefficient outcome arises whenever $b=7000$. From the numbers in parentheses in Table 8 we observe that this indeed applies; only in two instances we have $I>60$ together with $b=7000$. In line with theoretical predictions, when $b=7000$ the status quo outcome is (almost) always inefficient, and actual renegotiations are likely to take place.

Overall we conclude that the occurrence of renegotiations conditional on the actual investment made is well in line with theoretical predictions. Renegotiations mainly take place when there are efficiency gains to be made ex post. Yet under NC they sometimes occur when it is inefficient to do so. Non-equilibrium reliance levels do not appear to affect the actual occurrence of renegotiations (cf. the numbers within parentheses in Table 8). 
Table 9

Outcome of renegotiations of inefficient outcomes

\begin{tabular}{lllllll}
\hline \multirow{5}{*}{} & & \multicolumn{2}{l}{ Buyer's average share } & \# of rounds & $n$ \\
\cline { 3 - 6 } & & $\begin{array}{l}\text { Predicted } \\
(1)\end{array}$ & $\begin{array}{l}\text { Actual } \\
(2)\end{array}$ & $\begin{array}{l}\text { Equal split } \\
(3)\end{array}$ & $(4)$ & $(5)$ \\
\hline NC-Low & First & 1909 & 1445 & 1909 &. & 93 \\
& Accepted & 1888 & 1755 & 1888 & 1.61 & 85 \\
\multirow{2}{*}{ NC-High } & First & 1543 & 1283 & 1543 &. & 41 \\
& Accepted & 1544 & 1498 & 1544 & 1.58 & 40 \\
SP-Low & First & 5856 & 5347 & 3500 &. & 17 \\
& Accepted & 5853 & 5950 & 3500 & 1.88 & 16 \\
SP-High & First & 5621 & 4950 & 3500 &. & 60 \\
& Accepted & 5618 & 5675 & 3500 & 1.98 & 55 \\
\hline
\end{tabular}

Remark: \# of rounds gives the average number of bargaining rounds. $n$ denotes the number of observations.

For investment incentives the actual renegotiation outcomes are also important. We focus on the renegotiations that occur when the status quo appears to be inefficient (columns (1) and (2) in Table 8). ${ }^{27}$

Result 7. First and accepted offers under NC give Buyer on average a share below the predicted 'split-the-difference' solution. In case of SP accepted offers on average give Buyer her predicted share. In the absence of a contract Buyer gets a smaller return on investment than predicted.

Table 9 reports the outcome of actual renegotiations when the status quo appears to be inefficient. This table has the same setup as Table 4. Under both NC and SP first offers give Buyer on average a smaller share than the predicted 'split-the-difference' solution. Final agreements do give the buyer a larger share than first offers do. But in the process of getting a larger share some of the surplus is lost. Across Low and High, it takes on average 1.6 rounds to reach agreement under NC and almost 2 rounds under SP. On average Buyer is therefore better off by accepting Seller's initial offer.

To examine more closely the determinants of the bargaining results, we regressed first offers and accepted offers on the investment level, the squared investment level and a time trend. Results are reported in Table 10. Theoretically the sunk investment costs $I^{2}$ do not affect bargaining outcomes. However, under NC we do find that sunk costs matter. The coefficient on $I^{2}$ is significant. When we consider Sellers' first offers, the coefficient on $I$ appears insignificant. Because the coefficient for $I^{2}$ is less than one, the marginal return on investment always falls short of the marginal costs. For accepted offers the coefficient on $I$ appears to be significant. The marginal return on investment then equals $49 \%$ on average. ${ }^{28}$ This corresponds well with the predicted $50 \%$ marginal return. However, this return is

\footnotetext{
27 Under NC only 1 out of the 135 renegotiations of inefficient outcomes takes place after $b=7000$ (see the number in parentheses in Table 8). We excluded this observation and focus on those for $b=0$. Under SP all renegotiations of inefficient outcomes belong to $b=7000$.

28 With an average investment level of 25.56 this follows from: $15.7+2 \cdot 0.646 \cdot(25.56)=48.72$.
} 
Table 10

Regressions explaining first/accepted offers

\begin{tabular}{|c|c|c|c|c|c|c|}
\hline & \multicolumn{3}{|c|}{$\mathrm{NC}, b=0$} & \multicolumn{3}{|c|}{$\mathrm{SP}, b=7000$} \\
\hline & Pred. & First offer & Accepted & Pred. & First offer & Accepted \\
\hline Const. & 500 & $549(194)^{* * *}$ & $768(136)^{* * *}$ & 3400 & $2424(880)^{* * *}$ & $2415(382)^{* * *}$ \\
\hline$I$ & 50 & $13.9(10.8)$ & $15.7(7.65)^{* *}$ & 50 & $68.6(64.4)$ & $172(29.2)^{* * *}$ \\
\hline$I^{2}$ & 0 & $.575(.152)^{* * *}$ & $.646(.107)^{* * *}$ & 0 & $-.229(1.04)$ & $-2.02(.476)^{* * *}$ \\
\hline$t$ & 0 & $-4.65(15.3)$ & $-9.34(10.7)$ & 0 & $-.341(38.08)$ & $-4.31(16.9)$ \\
\hline$n$ & 144 & 134 & 125 & 96 & 77 & 71 \\
\hline Adj. $R^{2}$ & & .65 & .82 & & .19 & .59 \\
\hline
\end{tabular}

Remark: Regressions explaining Buyer's share. Standard deviations within parentheses. Significant coefficients at $1 \% / 5 \% / 10 \%$ level are marked with $* * * / * * / *$.

obtained only after some inefficient delay (cf. Table 9). The overall return on investment is thus less than predicted, supporting the last part of Result 7.

Under SP Sellers' first offers give Buyers a return on investment that is not significantly different from the predicted return of 50. For accepted offers the marginal return at the average investment level equals $-11.5 \% .^{29}$ This suggests that the realized marginal return on investment is smaller than the predicted (and initially offered) value of 50. It must be noted though that, in contrast to the no-contract situation, here renegotiations are not needed to obtain a return on investment. As long as no agreement has been reached, or when no renegotiations take place at all, Buyer gets a 100\% return through her threat point. A lower return on investment in the actual renegotiations may induce a lower willingness to enter these renegotiations, thereby increasing investment incentives. Indeed, in 13 out of the 16 cases in which parties did not renegotiate an inefficient outcome, it was Buyer who did not want to bargain. Therefore, for SP conclusions for the actual return on investment remain ambiguous.

Without a contract Buyer obtains a lower return on investment than predicted. However, the actual investment levels chosen under NC exceed the predicted ones (cf. Table 7). This suggests that Buyers do not choose the investment level that is optimal for them given actual bargaining outcomes. We estimated these "optimum" investment levels in the same way as we did for the sophisticated breach remedies. These are reported in Table 7 as well.

For NC the "optimum" investment levels do not differ significantly from zero. The variance in actual bargaining outcomes is then particularly large, resulting in large standard deviations. Relative to these calculated optima Buyer invests too much (from a selfish point of view). The finding that holdup is less severe than standard theory predicts is a rather robust one within the experimental economics literature. ${ }^{30}$ The explanation that is typically put forward is positive reciprocity. Investment by Buyer makes both agents potentially better off and thus can be considered a kind act. Seller might want to reward this kind behavior with a larger than predicted return. If such reciprocal behavior is anticipated, it is indeed optimal for Buyer to invest more than predicted. In the current experiment underinvestment is also less severe than predicted, but here Buyer's investment behavior is not optimal. One

\footnotetext{
${ }^{29}$ With an average investment level of 45.42 this follows from: $172-2 \cdot 2.02 \cdot(45.42)=-11.50$.

30 See e.g. Berg, Dickhaut, and McCabe (1995), Ellingsen and Johannesson (2004), Hackett (1994), Königstein (2000) and Sonnemans, Oosterbeek, and Sloof (2001).
} 
possible explanation why positive reciprocity does not justify our current finding of less holdup is the presence of a self-serving bias already mentioned in Section 4. Buyer may think that she deserves - and will be able to obtain - a high return on investment because she bears the full costs of investment. At the same time Seller may believe that he himself is entitled to a large return share to compensate him for (the possibility of) an unlucky draw of a low alternative trading opportunity. The asymmetry of the situation allows for such self-serving assessments. ${ }^{31}$ The settings in which positive reciprocity appears to work in alleviating holdup are typically more symmetric. Again it must be noted though that, in the absence of direct evidence on self-serving biases, this is merely our interpretation.

Also in the SP-High treatment Buyers tend to invest too much from a selfish perspective. Apart from a self-serving bias, another (arguably more convincing) explanation for this result is that some Buyers overlook that when their own threat point increases, the net surplus up for renegotiation decreases (when $b=7000$ ). They thus take the gross marginal return to be $100 \%$ in every contingency, making an investment of 50 optimal. Indeed, in the High-treatment the distribution of reliance levels is very concentrated around the mode of 50 (the frequency belonging to this mode exceeds 80\%). Under SP-Low actual investment levels are very close to the "optimum" ones.

\section{Efficiency comparison}

The ultimate aim of breach remedies is to increase efficiency. In this section we compare all five different cases of Sections 4 and 5 in terms of efficiency. Theory predicts that efficiency losses are solely due to inefficient investments. The breach and renegotiation stage cause no waste of the available surplus. The predicted efficiency ranking thus follows directly from investment incentives. In particular, theory predicts that in both the Low and the High-treatment efficiency is highest under LI. Our final result reveals that realized efficiency deviates from this prediction.

Result 8. (i) In the Low-treatment efficiency is highest under SP. Both investment and bargaining inefficiencies are smallest in this case. (ii) In the High-treatment efficiency is highest under NC. This is solely due to the small investment inefficiency under NC.

The result is supported by the findings on joint payoffs reported in Table 11. As before the amounts are normalized per bargaining round. Column (1) gives the expected joint payoffs when subjects make equilibrium choices. The second column contains the average realized joint payoffs. By subtracting these amounts from the maximum surplus $S\left(I^{*}\right)$ the overall observed inefficiencies are obtained. Columns (3) to (5) disentangle these into three different sources: investment inefficiency, bargaining inefficiency and residual inefficiency. Investment inefficiency equals the loss in expected surplus due to suboptimal investment. In calculating the investment inefficiency it is assumed that the bargaining stage is efficient.

\footnotetext{
$\overline{31}$ In the words of Babcock and Loewenstein (1997, p. 120): “. . . as soon as asymmetries are introduced between the parties - for example, different nonagreement values or costs of nonsettlement, or subtle differences in roles - both parties' notions of fairness will tend to gravitate toward settlements that favor themselves."
} 
Table 11

Joint payoffs and efficiency

\begin{tabular}{|c|c|c|c|c|c|c|c|c|}
\hline & & $\begin{array}{l}\text { Predicted } \\
\text { expected (1) }\end{array}$ & $\begin{array}{l}\text { Average } \\
\text { realized (2) }\end{array}$ & $\begin{array}{l}\text { Inv. ineff. } \\
\text { (3) }\end{array}$ & $\begin{array}{l}\text { Barg. } \\
\text { ineff. (4) }\end{array}$ & $\begin{array}{l}\text { Res. ineff. } \\
(5)\end{array}$ & $(1) / S\left(I^{*}\right)$ & $(2) / S\left(I^{*}\right)$ \\
\hline \multirow[t]{5}{*}{ Low } & $\mathrm{NC}$ & 3400 & $2586_{a b c d}$ & 332 & 842 & 40 & 0.89 & 0.68 \\
\hline & SP & 3775 & $3575_{a e f}$ & 121 & 100 & 4 & 0.99 & 0.94 \\
\hline & LI & 3800 & $2792_{\text {beg }}$ & 244 & 729 & 35 & 1 & 0.73 \\
\hline & $\mathrm{EX}$ & 3700 & $3292_{c g h}$ & 270 & 221 & 17 & 0.97 & 0.87 \\
\hline & $\mathrm{RE}$ & 3700 & $2725_{d f h}$ & 535 & 564 & -24 & 0.97 & 0.72 \\
\hline \multirow[t]{5}{*}{ High } & $\mathrm{NC}$ & 4900 & $4169_{i}$ & 248 & 535 & 48 & 0.98 & 0.83 \\
\hline & SP & 4775 & $3894_{j}$ & 823 & 331 & -48 & 0.96 & 0.78 \\
\hline & LI & 5000 & $4040_{k}$ & 518 & 367 & 75 & 1 & 0.81 \\
\hline & $\mathrm{EX}$ & 4100 & $3813_{l}$ & 921 & 225 & 41 & 0.82 & 0.76 \\
\hline & $\mathrm{RE}$ & 2275 & $2535_{i j k l}$ & 1940 & 527 & -2 & 0.46 & 0.51 \\
\hline
\end{tabular}

Remark: $S\left(I^{*}\right)=3800$ in the Low-treatments and $S\left(I^{*}\right)=5000$ in the High-treatments. It holds that $S\left(I^{*}\right)-(2)=$ $(3)+(4)+(5)$. Subscripts indicate that amounts within the second column are significantly different from each other according to a two-sided ranksum test (at the $10 \%$ level).

The bargaining inefficiency in column (4) is the sum of losses owing to parties deciding not to renegotiate when they should and losses due to delay of agreement. ${ }^{32}$ The third source of inefficiency is due to the fact that the empirical distribution of $b$ conditional on the investment level chosen may differ from the theoretical distribution. ${ }^{33}$ The resulting (in)efficiency cannot be attributed to subjects' decisions and is therefore referred to as residual inefficiency. The last two columns express predicted and actual joint payoffs as fractions of maximum expected joint payoffs $S\left(I^{*}\right)$.

Liquidated damages appear less efficient than predicted and are outperformed either by SP (Low-treatment) or NC (High-treatment). ${ }^{34}$ In the Low-treatment SP appears to be most efficient, both in terms of investment efficiency and in terms of bargaining efficiency. The reason that specific performance generates small investment inefficiencies in this treatment is that the variation in investment levels is very low. Although the average investment level under LI-Low (46.71) is closer to the efficient level of 40 than the level under SP-Low (49.88) is, there is much more variation in investment levels under LI-Low. While overand underinvestments cancel out and make the average investment under LI-Low closer to the efficient level, each deviation results in an efficiency loss that increases more than proportionally with the size of the deviation. Investment inefficiencies are therefore larger under LI-Low.

A potentional explanation for the large variation in investment levels under LI-Low is that Buyers have a hard time anticipating what the outcome of the breach and renegotiation stage will be. In contrast to the theoretical predictions renegotiations namely occur quite often under LI (cf. Result 3). As discussed in Section 4.2, around two-third of these renegotiations

\footnotetext{
32 Notice that the breach decision itself can never be a source of inefficiency because an inefficient breach decision can always be renegotiated.

33 Our design ensured that the realized frequencies of high outside bids exactly equalled 20 percent and 60 percent in the Low and High treatments respectively. That is, we controlled the unconditional empirical distribution of $b$. We did not control the distribution of $b$ conditional on the investment made.

34 Although note that the difference between LI-High and NC-High is not significant at the $10 \%$-level.
} 
are triggered by a non-equilibrium breach decision of Seller. Seller's breach decision thus adds "noise" to the process, because quite often a non-equilibrium choice is made. Also the outcomes of the renegotiations differ substantially from the predicted ones (cf. Result 4). This all may make it hard for Buyers to form correct expectations about the return on investment. In contrast, under SP-Low Buyers seem to have an easier task because renegotiations take place only when they are predicted to occur (cf. Result 6) and lead to outcomes which are fairly close to the predicted ones (cf. Result 7). This also explains why bargaining losses are small under SP-Low. Also under expectation damages relatively small amounts are wasted in the bargaining stage. This follows because very few pairs then actually enter the renegotiations.

In the High-treatment none of the breach remedies performs better than $\mathrm{NC}$ in terms of overall efficiency. Here the driving force is investment inefficiency. In the absence of a contract holdup is much less severe than predicted, keeping investment inefficiencies lower than predicted. Bargaining inefficiencies are substantial, as under all breach remedies considered.

The above findings indicate that when the probability $p$ that separation is efficient is low, parties are best off by signing a contract protected by a property rule (i.e. SP). In contrast, when $p$ is high it is in the parties' joint interest to write no contract at all. Theoretically SP is optimal only in the limit when $p \rightarrow 0$, while $\mathrm{NC}$ is optimal only when $p \rightarrow 1$. Our results suggest that empirically the cutoff values for $p$ making SP and NC optimal respectively, are considerably bounded away from these extreme values. The range of $p$-values for which it may be optimal to make elaborate contractual arrangements with sophisticated damage payments may thus be more limited than theory predicts.

For the LI, EX and RE treatments the efficiency levels can also be compared with those achieved in the no-renegotiation setup of Sloof et al. (2003). Interestingly, for all treatments efficiency levels are higher in the latter. Only in the RE-High treatment the difference is small. The explanation for this lies in two observations. First, reliance levels in the norenegotiation setup are somewhat closer to the efficient levels. The presence of renegotiation typically induces higher reliance levels on average, and thus more overreliance. Second, in the no-renegotiation setup losses due to suboptimal breach decisions appear to be small, while in the current setup we find substantial losses during the bargaining stage. Overall the introduction of ex post renegotiations appears to decrease efficiency.

\section{Conclusion}

This paper reports the outcomes of a series of laboratory experiments conducted to evaluate the performance of several commonly used breach remedies. These remedies all aim at alleviating the holdup problem that may induce underinvestment in relationship-specific assets. Theory suggests that some of the breach remedies lead to too much protection, as they are predicted to induce overinvestment. This result is driven by two motives to overinvest: the insurance motive and the separation prevention motive.

A previous paper (Sloof et al., 2003) considered breach remedies in a setting that did not allow for ex post renegotiation. There parties could not renegotiate the outcome that resulted after the breach decision stage. The results from this earlier experiment are almost 
completely in line with the theoretical predictions: under optimally designed liquidated damages reliance is efficient, under expectation damages the insurance motive is indeed present and under reliance damages also the separation prevention motive appears to be operative.

In reality it is very unlikely that the interaction between the contracting parties ends with a breach decision when this decision results in an inefficient outcome. A natural and important extension is therefore to give parties the opportunity of ex post renegotiation. This paper does so and tests whether the earlier results found for the different breach remedies carry over to this more realistic context. Apart from that, we also investigate the two benchmark cases of specific performance and no contract. In both these cases sophisticated breach remedies are absent. Either unilateral breach is not possible, or there is simply no contract that can be breached.

We obtain two main findings. First, also in a setting where ex post renegotiations are possible the insurance motive and the separation prevention motive are at work and cause overreliance. Specifically, in line with theoretical predictions the insurance motive is present under expectation damages, reliance damages and specific performance. The separation prevention motive is operative under reliance damages only. Together with those obtained in our earlier experiment these results indicate that the two overinvestment motives are very robust phenomena.

Our second main finding is that there seems less need for compensatory money damages than theory suggests. When ex ante separation is likely to be efficient (High-treatment), none of the breach remedies performs better than the no-contract situation. The main reason is that, without a contract, holdup appears much less of a problem than predicted. In the opposite case where ex ante the probability of efficient separation is low (Low-treatment), there is underinvestment in the absence of a contract. All breach remedies then significantly increase investment levels and thus serve the useful purpose of protecting specific investments. They do lead to different levels of efficiency though. In particular, under specific performance overinvestment is observed, as is predicted. But the overall inefficiencies observed under this remedy are very small. In this case specific performance outperforms all the sophisticated breach remedies in terms of efficiency, even though theory predicts that liquidated damages would be optimal.

In our experiment we included both the Low and the High-treatment, because comparing them allows an unambiguous and clean identification of the two motives to overinvest. From a more practical perspective, however, the Low-treatment is arguably the more relevant one. In practice parties will typically contract with partners with whom trade is likely to be efficient. Our results for the Low-treatment then suggest that a simple specific performance clause may perform better than a carefully determined liquidated damages breach remedy. Put differently, to protect reliance expenditures it may be preferable to use a "property rule" rather than a "liability rule".

As already noted in Section 1, various legal scholars have argued that in practice there may be an efficiency advantage for specific performance as the default remedy. The argument made is that, although specific performance may lead to costly haggling and inefficient outcomes, in practice compensatory money damages are likely to be under-compensatory. The latter may lead to larger inefficiencies than specific performance does. In this regard Mahoney (2000, p. 127) notes that: 
"The relative magnitudes of the inefficiencies generated by costly renegotiation and undercompensation are ultimately empirical questions and to date the literature does not provide data from which we could confidently identify the preferred remedy."

In our experiment we implemented the theoretically optimal liquidated damages payment, so the undercompensation problem was absent by construction. Even then it appears that, given actual behavior, specific performance performs best on efficiency grounds. Clearly, our experiment just provides a single piece of empirical evidence for a particular stylized situation, and much work remains to be done to establish how robust our results are. But we agree with Mahoney that the identification of the preferred breach remedy is ultimately an empirical issue.

\section{Acknowledgement}

We gratefully acknowledge the useful comments of an anonymous referee which improved the presentation of the material considerably.

\section{Appendix A}

This appendix contains translations of the computer-screens Buyers faced during the experiment. The example concerns the four-stage game of Section 2 for the case of reliance damages. In the simpler games of Section 5 the third stage is left out.

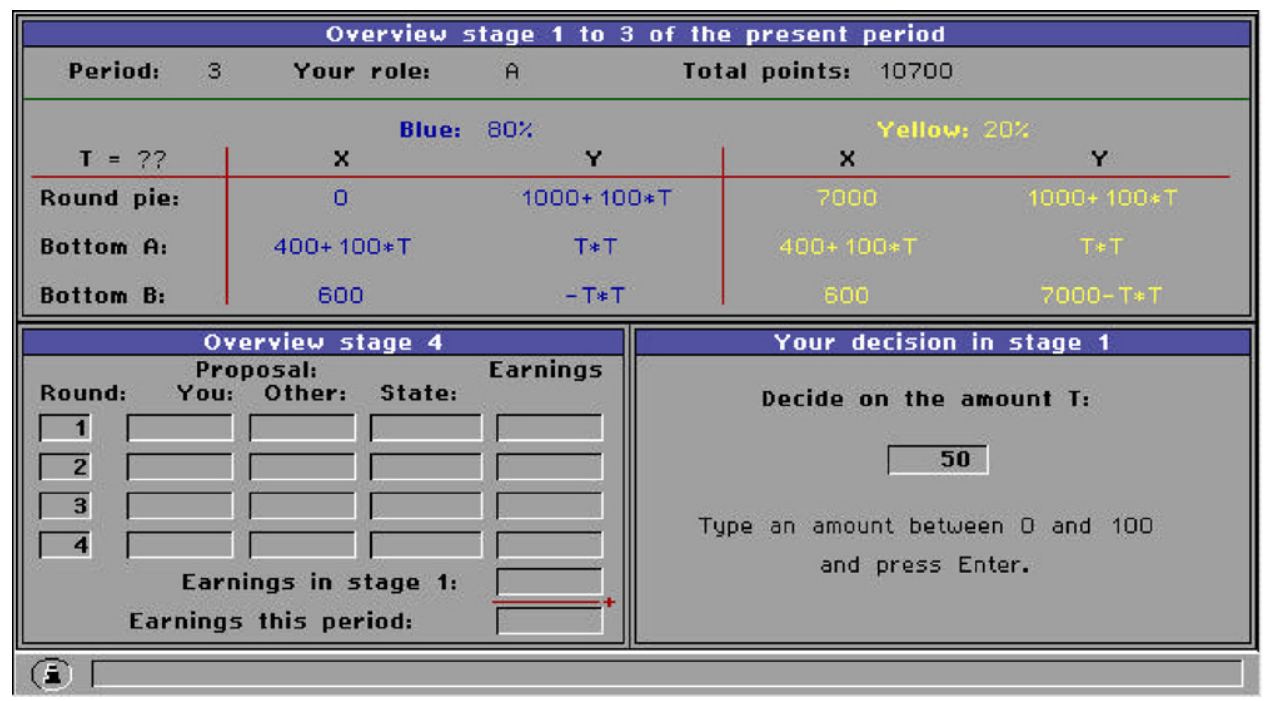

In the experiment Buyer has code 'A' and Seller code 'B'. In the overview at the top of the screen the pie sizes ('Round pie') and the threat points ('Bottom') are presented as formulas. When the subject enters the investment $\mathrm{T}$ in stage 1 , these formulas are replaced by numbers and the subject has to confirm or change the decision (not shown here). 


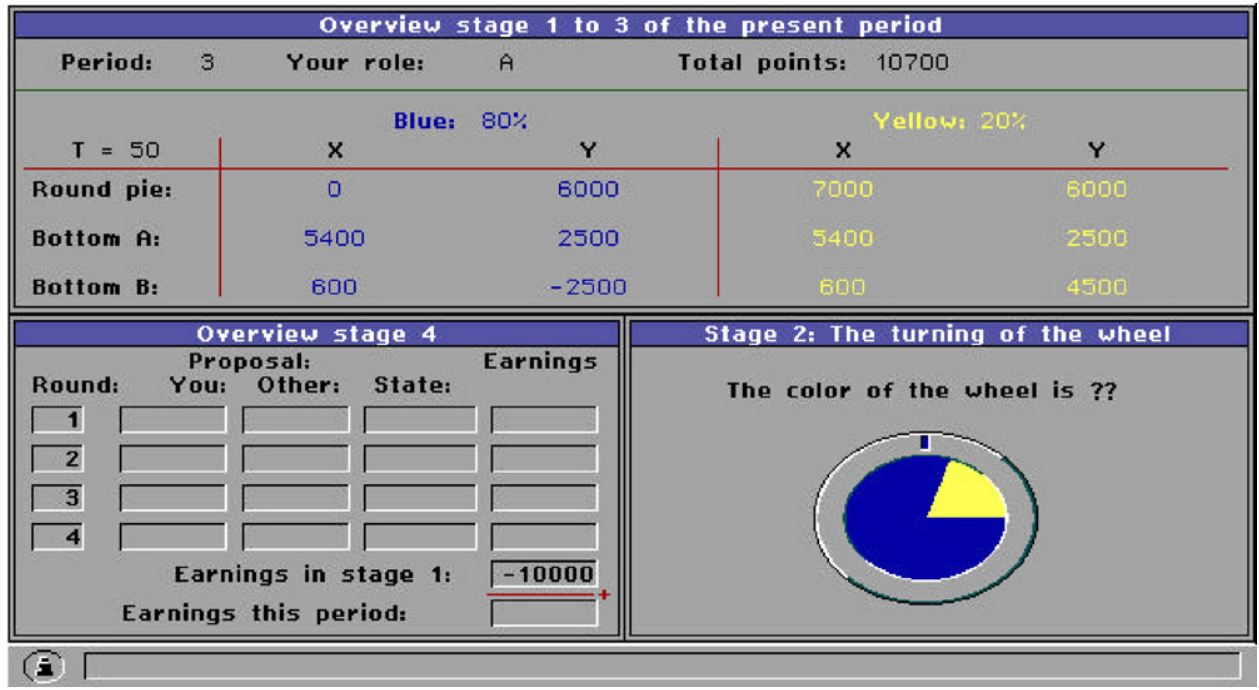

After the confirmation the wheel of fortune spins...

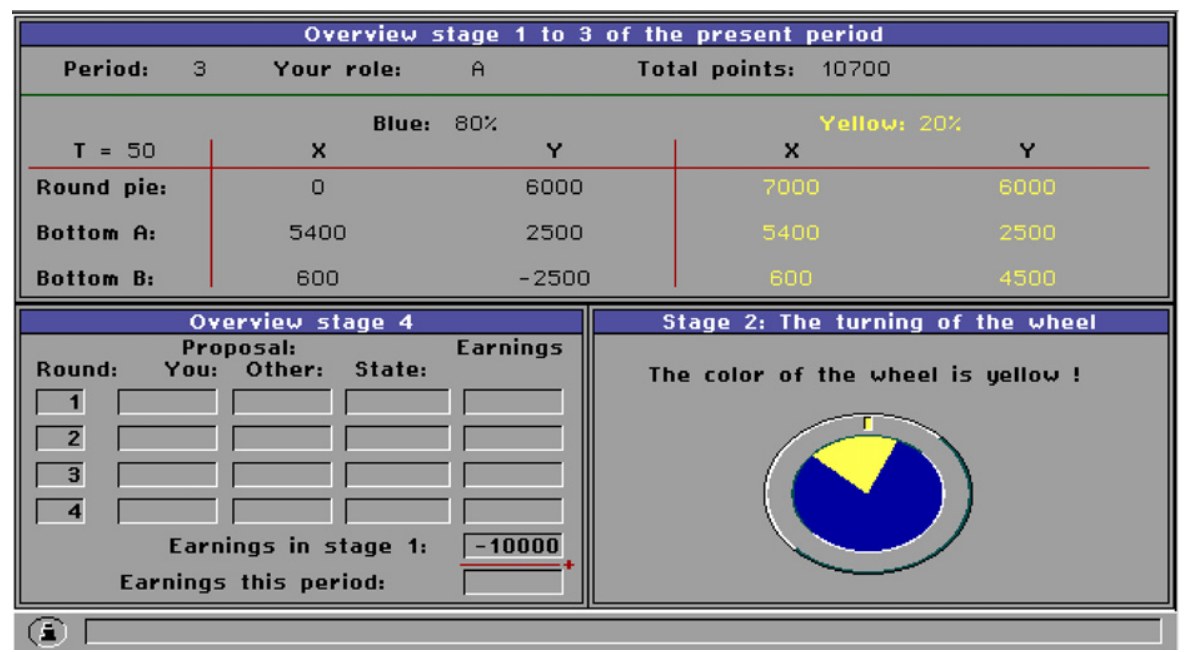

The outcome of the wheel of fortune is presented in the overview at top of the screen; the now irrelevant blue numbers have turned grey. 


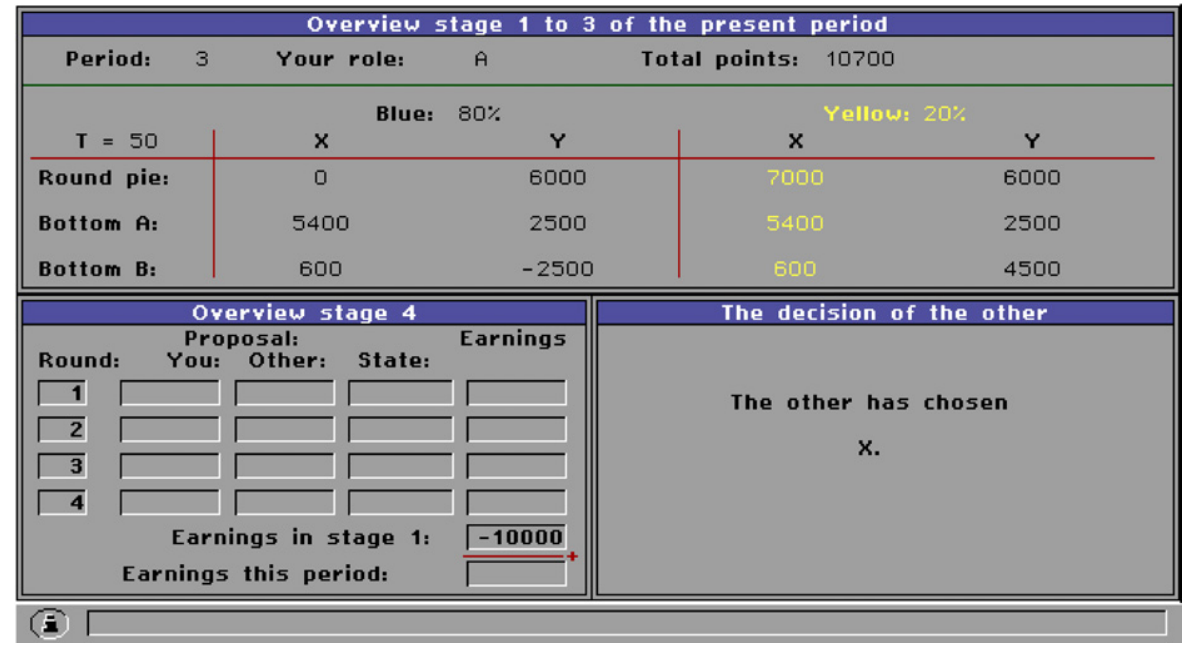

When Seller (B) has chosen ' $\mathrm{X}$ ' (No Breach) the now irrelevant yellow numbers under ' $Y$ ' have turned grey. (In the three-stage game of Section 5 this stage is absent; without a contract always case ' $Y$ ' applies (with the then appropriate numbers), under specific performance always case ' $\mathrm{X}$ ' applies.)

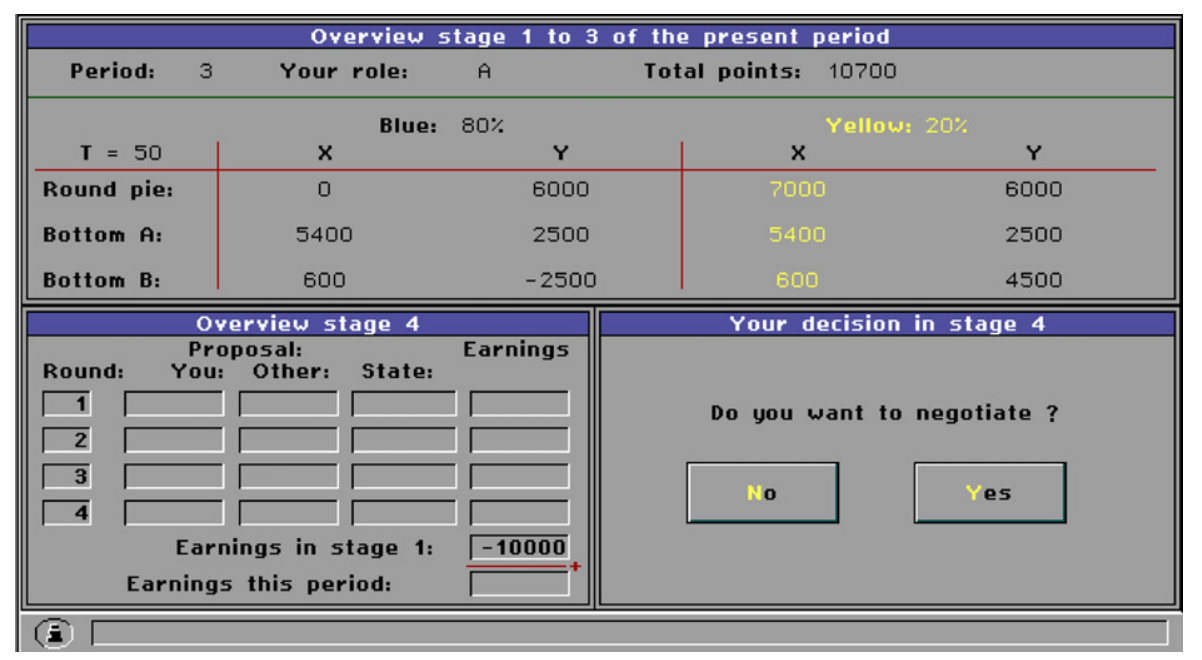

At the start of the final stage both subjects are asked whether they want to negotiate. 


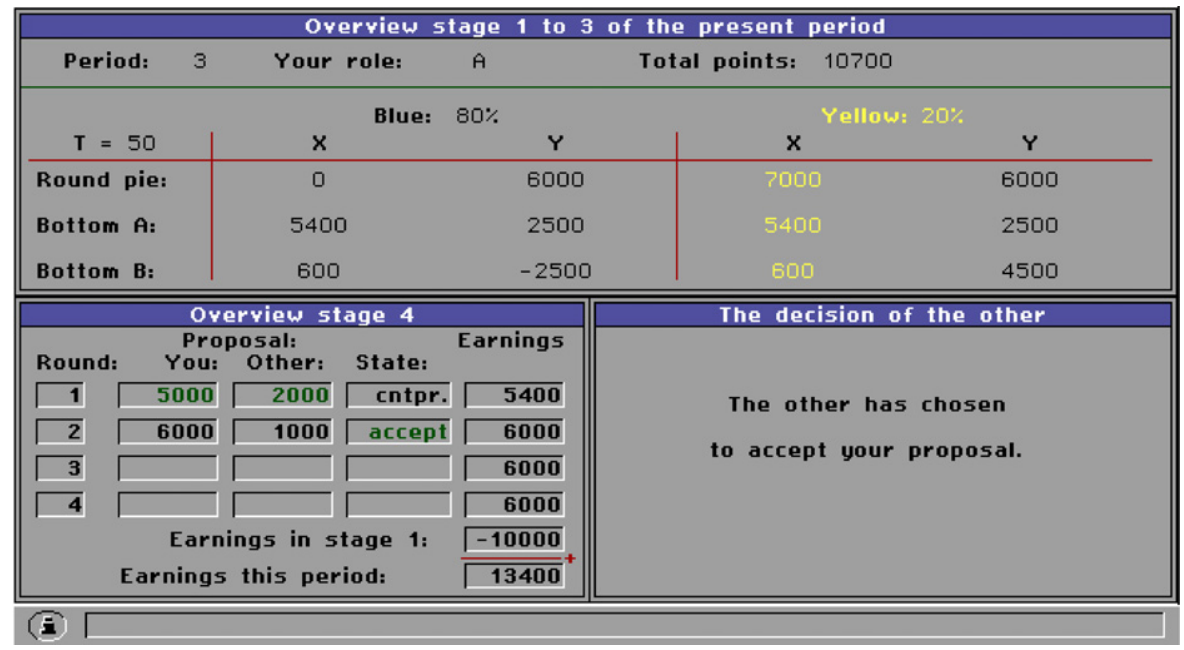

If both are willing to negotiate, the B-player (Seller) formulates the first proposal. The actions of the other player are always displayed in green while own actions always appear in black. Negotiations end when a proposal is accepted, or the fourth proposal is rejected.

\section{References}

Babcock, L., \& Loewenstein, G. (1997). Explaining bargaining impasse: The role of self-serving biases. Journal of Economic Perspectives, 11, 109-126.

Bebchuk, L. (2002). Ex ante investments and ex post externalities (Harvard Olin Discussion Paper No. 397).

Berg, J., Dickhaut, J., \& McCabe, K. (1995). Trust, reciprocity, and social history. Games and Economic Behavior, $10,122-142$.

Camerer, C. (2003). Behavioral game theory. Experiments in strategic interaction. Princeton University Press.

Che, Y. -K., \& Chung, T. -Y. (1999). Contract damages and cooperative investment. Rand Journal of Economics, $30,84-105$.

Cooter, R., \& Ulen, T. (1997). Law and Economics (2nd ed). Reading: Addison-Wesley.

Croson, R., \& Johnston, J. (2000). Experimental results on bargaining under alternative property rights regimes. Journal of Law, Economics and Organization, 16, 50-73.

Edlin, A. (1998). Breach remedies. In The new palgrave dictionary of ecnomics and the law. London: Macmillan.

Edlin, A., \& Hermalin, B. (2000). Contract renegotiation and options in agency problems. Journal of Law, Economics and Organisation, 16, 395-423.

Ellingsen, T., \& Johannesson, M. (2004). Is there a holdup problem?. Scandinavian Journal of Economics, 106, 475-494.

Hackett, S. (1994). Is relational exchange possible in the absence of reputations and repeated contract?. Journal of Law, Economics and Organization, 10, 360-389.

Jolls, C., Sunstein, C. R., \& Thaler, R. (1998). A behavioral approach to law and economics. Stanford Law Review, $50,1471-1550$.

Klein, B., Crawford, R., \& Alchian, A. (1978). Vertical integration, appropriable rents, and the competitive contracting process. Journal of Law and Economics, 21, 279-326.

Königstein, M. (2000). Equity, efficiency and evolutionary stability in bargaining games with joint production. Berlin Heidelberg: Springer Verlag. 
Lau, S. (2002). Information and bargaining in the hold-up problem (Working paper, Washington University in St. Louis.).

Mahoney, P. (2000). Contract remedies: General. In B. Bouckaert \& G. D. Geest (Eds.), Encyclopedia of law and economics (Vol. 3, pp. 117-140) [Chap. 4600]. Cheltenham: Edward Elgar.

Posner, R. A. (1977). Economic analysis of law (2nd ed). Boston: Little, Brown and Company.

Rogerson, W. (1984). Efficient reliance and damage measures for breach of contract. Rand Journal of Economics, $15,39-53$.

Schwartz, A. (1979). The case for specific performance. Yale Law Journal, 89, 271-307.

Segal, I., \& Whinston, M. (2000). Exclusive contracts and protection of investments. Rand Journal of Economics, 31, 603-633.

Shavell, S. (1980). Damage measures for breach of contract. Bell Journal of Economics, 11, 466-490.

Sloof, R. (2004). Finite horizon bargaining with outside options and threat points. Theory and Decision, 57, 109-142.

Sloof, R., Leuven, E., Oosterbeek, H., \& Sonnemans, J. (2003). An experimental comparison of reliance levels under alternative breach remedies. Rand Journal of Economics, 34, 205-222.

Sloof, R., Sonnemans, J., \& Oosterbeek, H. (2004). Specific investments, holdup, and the outside option principle. European Economic Review, 48, 1399-1410.

Sonnemans, J., Oosterbeek, H., \& Sloof, R. (2001). On the relation between asset ownership and specific investments. Economic Journal, 111, 791-820.

Ulen, T. (1998). Specific performance. In The new palgrave dictionary of economics and the law. London: Macmillan.

Williamson, O. (1985). The economic institutions of free capitalism. Free Press. 